\title{
A novel isotope pool dilution approach to quantify gross rates of key abiotic and biological processes in the soil phosphorus cycle
}

\author{
Wolfgang Wanek, David Zezula, Daniel Wasner, Maria Mooshammer, and Judith Prommer \\ Division of Terrestrial Ecosystem Research, Department of Microbiology and Ecosystem Science, Center of Microbiology \\ and Environmental Systems Science, University of Vienna, Althanstr. 14, 1090 Vienna, Austria
}

Correspondence: Wolfgang Wanek (wolfgang.wanek@univie.ac.at)

Received: 21 December 2018 - Discussion started: 15 January 2019

Revised: 26 June 2019 - Accepted: 9 July 2019 - Published: 9 August 2019

\begin{abstract}
Efforts to understand and model the current and future behavior of the global phosphorus $(\mathrm{P})$ cycle are limited by the availability of global data on rates of soil $\mathrm{P}$ processes, as well as their environmental controls. Here, we present a novel isotope pool dilution approach using ${ }^{33} \mathrm{P}$ labeling of live and sterile soils, which allows for high-quality data on gross fluxes of soil inorganic $\mathrm{P}\left(\mathrm{P}_{\mathrm{i}}\right)$ sorption and desorption, as well as of gross fluxes of organic $\mathrm{P}$ mineralization and microbial $\mathrm{P}_{\mathrm{i}}$ uptake to be obtained. At the same time, net immobilization of ${ }^{33} \mathrm{P}_{\mathrm{i}}$ by soil microbes and abiotic sorption can be easily derived and partitioned. Compared with other approaches, we used short incubation times (up to $48 \mathrm{~h}$ ), avoiding tracer remineralization, which was confirmed by the separation of organic $\mathrm{P}$ and $\mathrm{P}_{\mathrm{i}}$ using isobutanol fractionation. This approach is also suitable for strongly weathered and P-impoverished soils, as the sensitivity is increased by the extraction of exchangeable bioavailable $\mathrm{P}_{i}$ (Olsen $\mathrm{P}_{i} ; 0.5 \mathrm{M} \mathrm{NaHCO}_{3}$ ) followed by $\mathrm{P}_{\mathrm{i}}$ measurement using the malachite green assay. Biotic processes were corrected for desorption/sorption processes using adequate sterile abiotic controls that exhibited negligible microbial and extracellular phosphatase activities. Gross rates were calculated using analytical solutions of tracer kinetics, which also allowed for the study of gross soil P dynamics under non-steady-state conditions. Finally, we present major environmental controls of gross P-cycle processes that were measured for three P-poor tropical forest and three P-rich temperate grassland soils.
\end{abstract}

\section{Introduction}

Phosphorus $(\mathrm{P})$ is a major limiting nutrient to terrestrial primary production, particularly in highly weathered soils such as those found in the tropics. Globally, increasing imbalances between nitrogen $(\mathrm{N})$ and $\mathrm{P}$ inputs (i.e., increasing $\mathrm{N}: \mathrm{P}$ stoichiometry of inputs) caused by human activities and land-use changes through increased emissions of reactive $\mathrm{N}$ are suggested to lead to progressive $\mathrm{P}$ limitation of terrestrial ecosystems, and the first signs thereof have already been identified (Penuelas et al., 2013). A decrease in the relative $\mathrm{P}$ availability might have strong repercussions on future nutrient limitations of natural ecosystems, on food production and on carbon (C) sequestration (Penuelas et al., 2013; Penuelas et al., 2012; Yang et al., 2013). Efforts to understand and model the current and future global $\mathrm{P}$ cycle and its coupling to the global $\mathrm{C}$ and $\mathrm{N}$ cycles have been intensified, but are strongly limited by the availability of global data on soil gross $\mathrm{P}$ processes and their environmental controls (Reed et al., 2015). Therefore, large investments in new projects, experiments and models have recently been undertaken to advance our understanding of the terrestrial $\mathrm{P}$ cycle, and to fill data gaps, e.g., IMBALANCE-P (http://imbalancep-erc.creaf.cat, last access: 2 August 2019) and NGEE-Tropics (http://ngee-tropics.lbl.gov, last access: 2 August 2019).

Soil $\mathrm{P}_{\mathrm{i}}$ availability is governed by transfers of exchangeable $\mathrm{P}$ between pools (immobilized/fixed $\mathrm{P}$ and occluded $\mathrm{P}$ ), by the slow release of $\mathrm{P}_{\mathrm{i}}$ from mineral $\mathrm{P}$ via the weathering of primary minerals and by the mineralization of organic $\mathrm{P}$ $\left(\mathrm{P}_{\mathrm{o}}\right)$ (Fig. 1, this study; Bünemann, 2015; Turner et al., 2007). In strongly weathered soils, primary mineral $\mathrm{P}$ pools are depleted, and the largest fraction of $\mathrm{P}$ is found in occluded and 

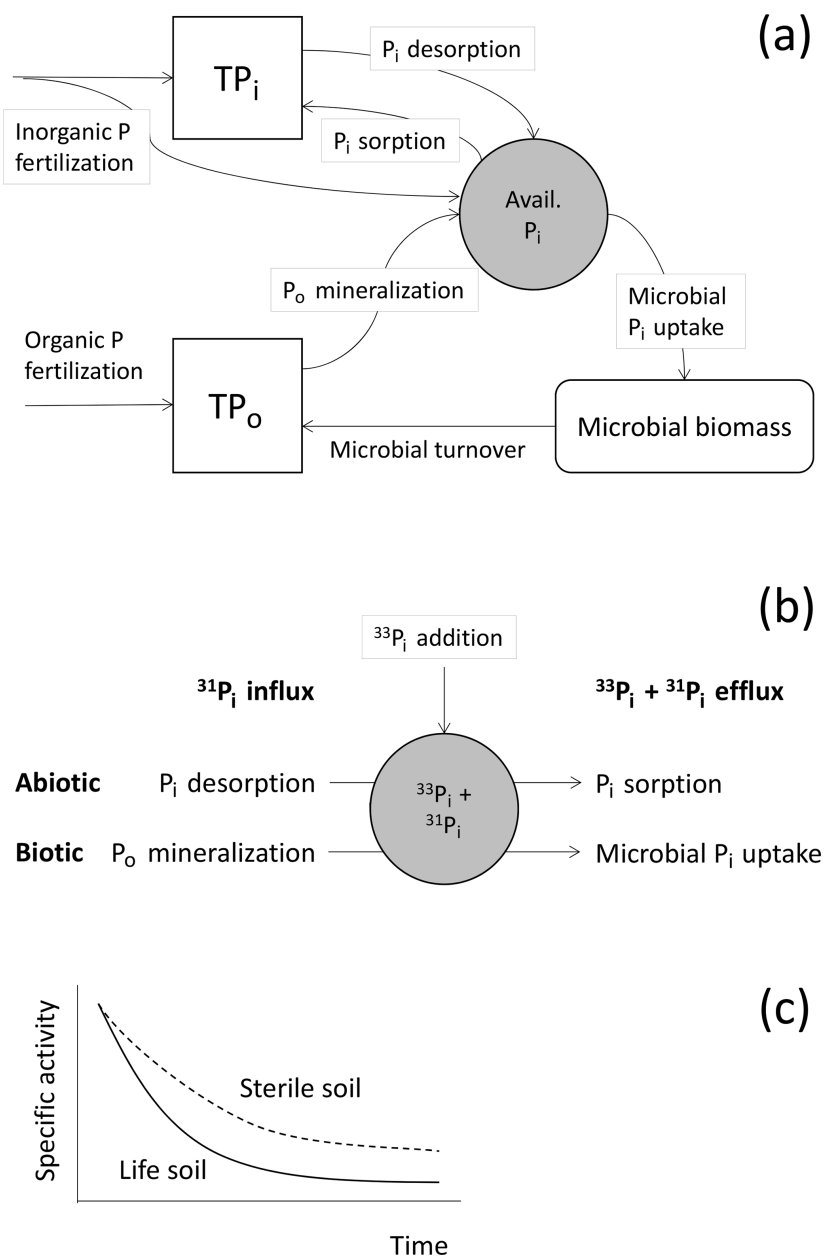

(c)

Figure 1. Schematic representation of (a) major fluxes of soil $\mathrm{P}$ processes controlling the availability of inorganic $\mathrm{P}\left(\mathrm{P}_{\mathrm{i}}\right)$ in soils, and of (b) the isotope pool dilution principle showing influxes of unlabeled $\mathrm{P}_{\mathrm{i}}\left({ }^{31} \mathrm{P}\right)$ into the available $\mathrm{P}_{\mathrm{i}}$ pool labeled by a spike in ${ }^{33} \mathrm{P}_{\mathrm{i}}$, and efflux of $\mathrm{P}_{\mathrm{i}}$ in the ratio of ${ }^{33} \mathrm{P}:{ }^{31} \mathrm{P}$ as present in the target pool. Biotic and abiotic processes of influx and efflux are presented. (c) This causes a decline in the specific activity of $\mathrm{P}_{\mathrm{i}}$, i.e., ${ }^{33} \mathrm{P}_{\mathrm{i}}:{ }^{31} \mathrm{P}_{\mathrm{i}}$ declines over time in sterile soils (abiotic processes only) and live soils (biotic plus abiotic processes), allowing for the biotic contributions to overall gross fluxes to be derived. $T P_{i}$ represents total soil $P_{i}$, and $\mathrm{TP}_{\mathrm{O}}$ represents total organic $\mathrm{P} ; \mathrm{TP}_{\mathrm{i}}$ includes occluded and fixed $\mathrm{P}$ as well as primary mineral $\mathrm{P}$, and $\mathrm{TP}_{\mathrm{O}}$ includes occluded $\mathrm{P}_{\mathrm{O}}$ in aggregates. Avail. refers to available. $\mathrm{P}_{\mathrm{i}}$ desorption includes $\mathrm{P}_{\mathrm{i}}$ dissolution from minerals, and $\mathrm{P}_{\mathrm{i}}$ sorption includes $\mathrm{P}_{\mathrm{i}}$ precipitation.

fixed pools, as well as in $\mathrm{P}_{\mathrm{o}}$ (Vitousek and Farrington, 1997; Yang and Post, 2011). Phosphorus limitation in such soils is further aggravated by their high $\mathrm{P}$ sorption potentials caused by high contents of $\mathrm{Fe}-\mathrm{Al}$ (hydr)oxides (Goldberg and Sposito, 1985). Most of the immediate P needs of plants (and microbes) in natural and agricultural systems are supplied by $\mathrm{P}_{\mathrm{o}}$ mineralization, catalyzed by extracellular phosphatases that are released by soil microbes and plant roots (Richardson and Simpson, 2011), as well as by abiotic $\mathrm{P}_{\mathrm{i}}$ desorp- tion. Soil microbes and plant roots can promote the release of $\mathrm{P}$ from primary and secondary minerals by accelerating mineral dissolution and $\mathrm{P}_{\mathrm{i}}$ desorption, via the exudation of (phyto)siderophores and organic acids (Mander et al., 2012; Ryan et al., 2001).

Soil $\mathrm{P}$ cycling processes such as soil $\mathrm{P}_{\mathrm{i}}$ sorption/desorption fluxes and gross $\mathrm{P}_{\mathrm{o}}$ mineralization rates, as well as the size of the exchangeable soil $P_{i}$ pool have been measured by isotope exchange kinetic (IEK) techniques using ${ }^{32} \mathrm{P}$ or ${ }^{33} \mathrm{P}$. These techniques are based on recurrent measurements of radiotracer recovery and $\mathrm{P}_{\mathrm{i}}$ concentration in soil water extracts ( $\mathrm{Di}$ et al., 1997; Frossard et al., 2011;Bünemann, 2015; Table 1, this study). A variety of IEK procedures and protocols are in use, and optimizations in methodology have been called for, particularly for $\mathrm{P}_{\mathrm{o}}$ mineralization (Bünemann, 2015). Only over the last decade have common, accepted protocols been adopted, and these protocols are currently used to measure soil $\mathrm{P}$ processes following Oehl et al. (2001b). In this IEK approach, abiotic sorption/desorption processes from an isotopically exchangeable $\mathrm{P}_{\mathrm{i}}$ pool are measured over a short time period in short-term batch experiments (100 min, $1: 10$ $(w: v)$ soil : water slurry, \pm microbicides). This assumes that no microbial tracer uptake (blocked by microbicides) and no organic P mineralization occurs, and that soils are in a steady state, i.e., do not show changes in $P_{i}$ concentration (Table 1). In such short-term IEK experiments the decrease in radioactivity (radiotracer recovery) in soil water is described by a power function:

$r(t) / R=r_{1 \min } / R x t^{-n}$,

where $R$ is the added radioactivity, and $r(t)$ is the radioactivity recovered at any time $t$ in soil water extracts. The parameters $r_{1 \mathrm{~min}} / R$ and $n$ (slope of the regression indicating speed of isotopic exchange) are derived from the log-log regression of $r(t)$ versus time. This is based on steady-state assumptions, i.e., that $\mathrm{P}_{\mathrm{i}}$ concentration in soil water extracts $\left(C_{\mathrm{P}}\right)$ is constant. In some soils an extended version of this equation needs to be applied:

$r(t) / R=m x\left(t+m^{1 / n}\right)^{-n}+r_{\text {inf }} / R$.

Here, $r_{\text {inf }} / R$ is the maximum possible dilution of the added radiotracer, approximated as the ratio of $C_{\mathrm{P}}$ to total inorganic $\mathrm{P}$ in soils. $\mathrm{n}$ and $\mathrm{m}$ are derived from non-linear fitting procedures. Assuming that the tracer and tracee behave similarly in the system, the specific activity of $P_{i}$ in the soil solution should reflect the specific activity of isotopically exchangeable $\mathrm{P}$ - termed the $E$ value (in $\mathrm{mg} \mathrm{P} \mathrm{kg}^{-1}$ soil).

$E_{(t)}=C_{\mathrm{P}} /(r(t) / R)$.

Isotopic dilution, $E^{\prime}(t)$, is further measured over the full length of a moist soil incubation experiment lasting for several days to weeks, constituting the total amount of exchangeable $\mathrm{P}_{\mathrm{i}}$ or isotope dilution caused by concurrent biological processes $\left(\mathrm{P}_{\mathrm{o}}\right.$ mineralization) and physicochemical 
Table 1. Comparison of traditional isotope exchange kinetic kinetic (IEK) experiments and the novel isotope pool dilution (IPD) approach to measure organic $\mathrm{P}$ mineralization.

\begin{tabular}{|c|c|c|}
\hline Factor and approach & Isotope exchange (IEK) & Isotope pool dilution (IPD) \\
\hline $\begin{array}{l}\text { Tracer addition and in- } \\
\text { cubation period }\end{array}$ & $\begin{array}{l}{ }^{33} \mathrm{P},{ }^{32} \mathrm{P} \\
\text { several time points across several days to weeks and } \\
\text { months }\end{array}$ & $\begin{array}{l}{ }^{33} \mathrm{P},\left({ }^{32} \mathrm{P}\right) \\
\text { two time points at } 4 \text { and } 24 \mathrm{~h}\end{array}$ \\
\hline Measured P pool & Water-extractable $\mathrm{P}_{\mathrm{i}}$ & Bicarbonate-extractable $\mathrm{P}_{\mathrm{i}}$ and $\mathrm{P}_{\mathrm{O}}$ \\
\hline Abiotic controls & $\begin{array}{l}\text { Abiotic controls measured in batch experiment with live } \\
\text { soil: } 100 \text { min } \mathrm{P}_{\mathrm{i}} \text { exchange experiment in soil suspen- } \\
\text { sion } 1: 10 \text { (soil : water), } \pm \mathrm{HgCl}_{2} \text { or sodium azide; mi- } \\
\text { crobial contributions in short-term experiment often not } \\
\text { accounted for }\end{array}$ & $\begin{array}{l}\text { Duplicate autoclaving for abiotic controls to kill } \\
\text { microbial biomass and extracellular enzymes; } \\
\text { treatment of abiotic controls similar to live soils } \\
\text { in terms of tracer addition, incubation period } \\
\text { and extraction }\end{array}$ \\
\hline $\begin{array}{l}\text { Microbial processes in } \\
\text { abiotic controls }\end{array}$ & $\begin{array}{l}\text { Microbial biomass active in abiotic controls if no mi- } \\
\text { crobicide added, extracellular phosphatases fully active } \\
\text { (causing organic } \mathrm{P} \text { mineralization in abiotic controls) }\end{array}$ & $\begin{array}{l}\text { Microbial biomass and phosphatases deacti- } \\
\text { vated by autoclaving (no/almost no P mineral- } \\
\text { ization occurring in abiotic controls) }\end{array}$ \\
\hline $\begin{array}{l}\text { Preincubation of soils } \\
\text { to equilibrate to mois- } \\
\text { ture and temperature }\end{array}$ & $\begin{array}{l}\text { Yes (to constant respiration - equilibrium conditions } \\
\text { necessary) }\end{array}$ & Yes (not necessary) \\
\hline $\begin{array}{l}\text { Change in soil structure } \\
\text { and } \mathrm{P} \text { availability }\end{array}$ & No (if no microbicide is added) & $\begin{array}{l}\text { Potentially yes, as autoclaving might increase } \\
\text { available P by death of microbial biomass and } \\
\text { soil structure might change by autoclaving }\end{array}$ \\
\hline $\begin{array}{l}\text { Numerical solution for } \\
\mathrm{P}_{\mathrm{O}} \text { mineralization }\end{array}$ & $\begin{array}{l}\text { Isotopically exchangeable } \mathrm{P} \text { within } t \text { minutes, } E_{(t)} \text {, } \\
\text { derived as the inverse of the relative specific activ- } \\
\text { ity of phosphate in soil solution (water extractable } \mathrm{P}_{\mathrm{i}} \text { ) } \\
\text { over time in live soils. } E^{\prime}(t) \text { derived for abiotic con- } \\
\text { trols extrapolated from } 100 \text { min to length of full ex- } \\
\text { periment, graphical solution of corrected data following } \\
\text { Fardeau (1993). Differences in } E^{\prime}{ }_{(t)} \text { and } E_{(t)} \text { estimate } \\
\text { gross } \mathrm{P}_{\mathrm{O}} \text { mineralization }\end{array}$ & $\begin{array}{l}\text { Calculation of IPD influx rates based on } \\
\text { mass/isotope balance equations derived by } \\
\text { Kirkham and Bartholomew (1954) for tracer: } \\
\text { tracee experiments. Gross } \mathrm{P}_{\mathrm{O}} \text { mineralization } \\
\text { calculated as difference of IPD influx rates of } \\
\text { live soils minus abiotic controls }\end{array}$ \\
\hline
\end{tabular}

processes. Short-term exchange kinetics are then extrapolated over the full time period of the moist soil incubation, $E_{(t)}$ (Fardeau et al., 1991). The difference between $E^{\prime}(t)$ and the extrapolated $E_{(t)}$ value then provides the measure of gross $\mathrm{P}_{\mathrm{o}}$ mineralization.

The isotope pool dilution approach (IPD) of Kirkham and Bartholomew (1954) was developed as a general tracer approach to measure gross rates of soil element cycle processes, but was most frequently applied to nitrogen cycling processes such as organic $\mathrm{N}$ mineralization and nitrification (Booth et al., 2005). However, the IPD approach can also be transferred to measure gross rates of $\mathrm{P}$ cycle processes (Di et al., 2000). It then also relies on the labeling of the $\mathrm{P}_{\mathrm{i}}$ pool with ${ }^{33} \mathrm{P}$ or ${ }^{32} \mathrm{P}$ and on subsequent timeresolved measurements of concentrations and specific activities of $\mathrm{P}_{\mathrm{i}}$ (Table 1, Fig. 1b). However, in contrast to IEK techniques, changes in $\mathrm{P}_{\mathrm{i}}$ concentrations and specific activities are then solved by mass balance equations developed specifically for gross rate calculations based on tracer studies (Kirkham and Bartholomew, 1954). In the following we list the criteria that have to be met by the IPD method to cor- rectly determine gross rates of soil $\mathrm{P}_{\mathrm{o}}$ mineralization and soil $\mathrm{P}_{\mathrm{i}}$ sorption/desorption (Di et al., 2000; Murphy et al., 2003; Kirkham and Bartholomew, 1954).

1. The tracer $\left({ }^{32} \mathrm{P}_{\mathrm{i}}\right.$ or $\left.{ }^{33} \mathrm{P}_{\mathrm{i}}\right)$ and tracee (unlabeled $\left.{ }^{31} \mathrm{P}_{\mathrm{i}}\right)$ behave identically and are well mixed. This is given for the different isotopes of $\mathrm{P}$ as long as radiotracer solution is homogeneously distributed in the soil and sufficient time is provided for isotope equilibration between added radiotracer and the native $\mathrm{P}_{\mathrm{i}}$ pool.

2. The influx into the target $\left(\mathrm{P}_{\mathrm{i}}\right)$ pool (i.e., the product of $\mathrm{P}_{\mathrm{O}}$ mineralization) has to be unlabeled (i.e., no tracer remineralization), in order for it to dilute the tracer: tracee ratio over time (Fig. 1b, c). Tracer remineralization via microbial tracer assimilation, mortality and subsequent remineralization of labeled $\mathrm{P}_{\mathrm{O}}$ would result in an underestimation of $\mathrm{P}_{\mathrm{o}}$ mineralization, but can be avoided by short incubation times (1-2 d).

3. Abiotic release of $\mathrm{P}_{\mathrm{i}}$ from a non-extractable pool $\left(\mathrm{P}_{\mathrm{i}}\right.$ desorption) causes an influx of unlabeled $\mathrm{P}_{\mathrm{i}}$ into the tar- 
get pool, resulting in an overestimation of the biotic process, $\mathrm{P}_{\mathrm{o}}$ mineralization, and has to be determined in parallel abiotic incubations of sterile soils. However, adequate abiotic controls with no contribution of biological processes have remained a major obstacle in measuring soil P dynamics with radiotracers, both in IEK and IPD experiments. Procedures in earlier studies ranged from short-term assays with no inhibitor addition as often performed in IEK assays (Spohn et al., 2013; Oehl et al., 2001b), to amendments of $\mathrm{HgCl}_{2}$, sodium azide, toluene or chloroform, and gamma irradiation or repeated autoclaving (Kellogg et al., 2006; Bünemann, 2015; Bünemann et al., 2007; Oehl et al., 2001b; Achat et al., 2010).

4. The soil extraction should target the bioavailable exchangeable $\mathrm{P}_{\mathrm{i}}$ pool. $\mathrm{P}_{\mathrm{i}}$ in soil solution undergoes rapid equilibration with easily adsorbed $\mathrm{P}_{\mathrm{i}}$. An incomplete extraction of this pool causes an underestimation of $P_{o}$ mineralization rates, due to desorption from this pool, causing an influx of unlabeled tracer (and unlabeled $\mathrm{P}_{\mathrm{i}}$ ) into the target pool, and thus violates assumption no. 2 of IPD assays. The commonly used soil water extractions target only a small fraction of this target pool, whereas standard soil P extractants, such as Olsen, Mehlich 3 or Bray 1, extract a larger fraction (Kleinman et al., 2001) and, therefore, are suggested to be better suited to extract the rapidly exchanging $\mathrm{P}_{\mathrm{i}}$ pool (Kel$\operatorname{logg}$ et al., 2006).

5. The efflux from the isotopically labeled pool (i.e., microbial $\mathrm{P}_{\mathrm{i}}$ immobilization and $\mathrm{P}_{\mathrm{i}}$ sorption into a nonextractable pool) occurs at the ratio of tracer: tracee as present in the $P_{i}$ pool at any specific time, with no discrimination between native $P_{i}$ and added radiotracer (Fig. 1b). A short preincubation time is therefore needed to allow for full mixing and isotopic equilibration of tracer and tracee (see point no. 1).

6. Changes in specific activity need to be measured specifically in the target pool, i.e., in extractable $\mathrm{P}_{\mathrm{i}}$ for measurements of gross rates of $\mathrm{P}_{\mathrm{o}}$ mineralization and $\mathrm{P}_{\mathrm{i}}$ sorption/desorption. However, most current approaches do not separate extractable $\mathrm{P}_{\mathrm{i}}$ and $\mathrm{P}_{\mathrm{o}}$ but measure radioactivity in unfractionated extracts, including radiolabeled $\mathrm{P}_{\mathrm{o}}$ formed during the incubation, leading to an eventual overestimation of $\mathrm{P}_{\mathrm{o}}$ mineralization.

7. The rates of $P_{i}$ influx $\left(P_{o}\right.$ mineralization, abiotic $P_{i}$ release) and $P_{i}$ efflux (biotic and abiotic $P_{i}$ immobilization) need to be constant over the duration of incubation: (i) the initial phase of fast immobilization by sorption, microbial uptake and isotopic equilibration of radiotracer is excluded from calculations of gross rates, and (ii) incubation takes place within a suitable time frame to avoid microbial turnover and ${ }^{33} \mathrm{P}_{\mathrm{o}}$ remineralization (see point no. 2). The minimum two time points necessary to measure concentration and specific activity of $P_{i}$ for the IPD calculations should therefore lie in between the initial phase and the start of remineralization, but it is recommendable to test more time points in the beginning to test the time linearity of IPD rates for specific soil types.

Mooshammer et al. (2012) adopted such a protocol for measurements of gross $P_{0}$ mineralization in decomposing plant litter, following the knowledge of IPD processes based on ${ }^{15} \mathrm{~N}$ additions to study gross rates of soil $\mathrm{N}$ cycling (Hart et al., 1994; Murphy et al., 2003; Wanek et al., 2010; Braun et al., 2018). However, in plant litter P sorption and the abiotic release of $\mathrm{P}_{\mathrm{i}}$ from sorbed $\mathrm{P}$ pools do not interfere. Consequently, the litter protocol cannot be directly transferred to soil studies. In the present study we developed an IPD protocol to assess soil $\mathrm{P}$ dynamics, based on the previous work for litter by Mooshammer et al. (2012) and soils by Kellogg et al. (2006). The protocol is based on IPD theory (Kirkham and Bartholomew, 1954; Di et al., 2000) applied to parallel incubations of live and sterile soil with ${ }^{33} \mathrm{P}_{\mathrm{i}}$ tracer addition. Gross rates of $P_{i}$ sorption (abiotic immobilization) and $P_{i}$ desorption are determined in sterile soils, and allow for the correction of gross $\mathrm{P}_{\mathrm{o}}$ mineralization and microbial $\mathrm{P}_{\mathrm{i}}$ immobilization rates in live soils. We used bicarbonate extractions to target the bioavailable exchangeable $\mathrm{P}_{\mathrm{i}}$ pool. To avoid tracer remineralization, we used short incubation periods (up to $2 \mathrm{~d}$ ). To confirm that no significant amount of ${ }^{33} \mathrm{P}_{\mathrm{o}}$ was formed during incubation, $\mathrm{P}_{\mathrm{i}}$ was also separated from $\mathrm{P}_{\mathrm{o}}$ based on isobutanol fractionation (Jayachandran et al., 1992). $P_{i}$ concentrations were measured based on the phosphomolybdate blue protocol. At very low $\mathrm{P}_{\mathrm{i}}$ concentrations, e.g., in tropical soils, which are below the detection limit of the phosphomolybdate blue method, $\mathrm{P}_{\mathrm{i}}$ was determined by parallel measurements of $\mathrm{P}_{\mathrm{i}}$ in bicarbonate extracts using the more sensitive malachite green assay (D'Angelo et al., 2001; Ohno and Zibilske, 1991). The protocol was tested rigorously with two different soils, and then applied to six soils in total (three tropical forest and three temperate grassland soils) to explore environmental controls on gross soil P dynamics.

\section{Materials and methods}

\subsection{Soil materials and basic characterization}

Soils ( $0-15 \mathrm{~cm}$ depth) were collected in summer 2015 from three temperate grassland sites in Austria and in spring 2015 from three tropical lowland forest sites in Costa Rica (Table 2). The grassland soils were extensively managed meadows, collected in Lower Austria $\left(48^{\circ} 13-20^{\prime} \mathrm{N}, 16^{\circ} 12-17^{\prime} \mathrm{E}\right)$ in the vicinity of Vienna, at elevations between 170 and $320 \mathrm{~m}$. The tropical forest soils were collected along a topographic gradient (ridge-slope-valley bottom) in wet evergreen old-growth forests in southwestern Costa Rica close to the Piedras Blancas National Park $\left(8^{\circ} 41^{\prime} \mathrm{N}, 83^{\circ} 12^{\prime} \mathrm{W}, 110\right.$ 
Table 2. Soil characterization of three temperate grassland soils (soil 2, 4 and 6) and three tropical lowland forest soils (soil 3, 5 and 7).

\begin{tabular}{|c|c|c|c|c|c|c|c|}
\hline \multirow[t]{2}{*}{ Parameter } & \multirow[t]{2}{*}{ Unit } & \multicolumn{3}{|c|}{ Temperate soils } & \multicolumn{3}{|c|}{ Tropical soils } \\
\hline & & 2 & 4 & 6 & 3 & 5 & 7 \\
\hline Soil pH $\left(10 \mathrm{mMCaCl}_{2}\right)$ & & 6.30 & 6.25 & 6.80 & 4.15 & 4.15 & 4.10 \\
\hline Clay & $(\%)$ & 16.8 & 14.1 & 2.76 & 4.12 & 19.6 & 26.2 \\
\hline Silt & $(\%)$ & 59.2 & 24.4 & 40.6 & 88.0 & 72.8 & 70.1 \\
\hline Sand & $(\%)$ & 24.0 & 61.4 & 56.6 & 7.92 & 7.61 & 3.74 \\
\hline Total organic $\mathrm{C}$ & $\left(\mathrm{mg} \mathrm{g}^{-1}\right.$ soil dw $)$ & 48.3 & 126.7 & 60.3 & 26.4 & 30.8 & 28.5 \\
\hline Total N & $\left(\mathrm{mg} \mathrm{g}^{-1}\right.$ soil dw $)$ & 3.35 & 5.03 & 2.32 & 2.17 & 2.57 & 2.27 \\
\hline Total P (TP) & $\left(\mathrm{mg} \mathrm{g}^{-1}\right.$ soil dw) & 0.82 & 0.44 & 0.51 & 0.14 & 0.17 & 0.09 \\
\hline Total organic $\mathrm{P}\left(\mathrm{TP}_{\mathrm{O}}\right)$ & $\left(\mathrm{mg} \mathrm{g}^{-1}\right.$ soil dw) & 0.40 & 0.25 & 0.11 & 0.09 & 0.13 & 0.07 \\
\hline Soil $\mathrm{P}_{\mathrm{i}}$ & $\left(\mu \mathrm{gg}^{-1}\right.$ soil dw $)$ & 15.1 & 4.23 & 5.59 & 0.56 & 0.49 & 0.37 \\
\hline $\mathrm{TP}_{\mathrm{O}}$ of $\mathrm{TP}$ & $(\%)$ & 49.1 & 56.5 & 22.3 & 64.2 & 75.7 & 76.4 \\
\hline Soil C : N & & 14.4 & 25.2 & 26.0 & 12.1 & 12.0 & 12.5 \\
\hline Soil $\mathrm{C}: \mathrm{TP}_{\mathrm{O}}$ & & 121 & 507 & 548 & 293 & 237 & 406 \\
\hline Soil $\mathrm{N}$ : $\mathrm{TP}_{\mathrm{O}}$ & & 8.4 & 20.1 & 21.1 & 24.1 & 19.8 & 32.5 \\
\hline Phosphatase & $\left(\right.$ nmol MUF g ${ }^{-1}$ soil dw $^{-1}$ ) & 256 & 316 & 233 & 1396 & 1698 & 2346 \\
\hline
\end{tabular}

$250 \mathrm{~m}$ a.s.l.). Soils were sieved to $2 \mathrm{~mm}$ and stored in an airdried state. Soil $\mathrm{pH}$ was measured in a 1:5 $(w: v)$ mixture of air-dried soil in water after $60 \mathrm{~min}$ of equilibration using an ISFET electrode (Sentron SI600 pH meter). Soil texture was quantified using a miniaturized pipette/sieving protocol for 2-4 g air-dried soils (Miller and Miller, 1987), using $4 \%$ sodium metaphosphate as a dispersant. Soil total C and total soil $\mathrm{N}$ content were determined after grinding oven-dried soil in a ball mill, using an elemental analyzer (EA 1110, CE Instruments, Thermo Scientific). Temperate grassland soils were treated with $2 \mathrm{M} \mathrm{HCl}$ to remove carbonates, re-dried, ground and then analyzed using an elemental analyzer for soil organic $\mathrm{C}$. Total soil $\mathrm{P}$ and total soil $\mathrm{P}_{\mathrm{i}}$ were measured after $0.5 \mathrm{M} \mathrm{H}_{2} \mathrm{SO}_{4}$ extraction of ignited soils $\left(5 \mathrm{~h}\right.$ at $450{ }^{\circ} \mathrm{C}$ in a muffle furnace; O'Halloran and Cade-Menun, 2008) and of untreated soils, respectively, using the malachite green method (Ohno and Zibilske, 1991; D'Angelo et al., 2001). Total organic $\mathrm{P}$ was estimated by calculating the difference between total soil $\mathrm{P}$ and total soil $\mathrm{P}_{\mathrm{i}}$. We must, however, submit that ignition methods tend to overestimate soil organic $\mathrm{P}$ in highly weathered tropical soils (Condron et al., 1990).

\subsection{Soil pretreatment and assay of sterilization efficiency (abiotic controls)}

Before starting the experiments, the soils were reequilibrated from an air-dried state by rewetting to $60 \%$ water holding capacity for $6 \mathrm{~d}$ at $20^{\circ} \mathrm{C}$. Gravimetric soil water content and water holding capacity were determined prior to the experiment. Soils were then either sterilized twice, 48 and $2 \mathrm{~h}$ before the start of the IPD experiments, by autoclaving at $121^{\circ} \mathrm{C}$ for $60 \mathrm{~min}$ (sterile soils), or were kept at $20^{\circ} \mathrm{C}$ (live soils, Fig. 2). Sterilization efficiency was checked based on soil enzyme activity measurements. Fluorescein diacetate (FDA) hydrolysis in soils was measured as a proxy of vi- able, active microbial biomass (Green et al., 2006; Schnurer and Rosswall, 1982), and the activity of acid phosphomonoesterases, which are extracellular enzymes involved in $\mathrm{P}_{\mathrm{o}}$ mineralization, was determined using methylumbelliferyl (MUF) phosphate (Sirova et al., 2013; Marx et al., 2001).

\section{$2.3 \quad{ }^{33} \mathrm{P}$ IPD assay}

A schematic representation of the final IPD protocol can be found in Fig. 2. Duplicate soil aliquots (2 $g$ fresh weight) of sterile and live soil were each amended with $20 \mathrm{kBq}^{33} \mathrm{P}_{\mathrm{i}}$ (dilution of orthophosphoric acid phosphorus-33 radionuclide, $5 \mathrm{~m} \mathrm{Ci} \mathrm{mL}^{-1}$, i.e., $185 \mathrm{MBq} \mathrm{mL}^{-1} \mathrm{HCl}$-free water at a specified date, Perkin NEZ080002MC). Between 0.15 and $0.2 \mathrm{~mL}$ of ${ }^{33} \mathrm{P}$-label solution was added to each sample (Fig. 2); the volume added was adjusted for each soil type to obtain an optimal water content in each soil ( $\sim 75 \%$ water holding capacity). Soils were extracted with $30 \mathrm{~mL}$ (temperate soils) or $15 \mathrm{~mL}$ (tropical soils) of $0.5 \mathrm{M} \mathrm{NaHCO}_{3}(\mathrm{pH} \mathrm{8.5)}$ ) after 4 and $24 \mathrm{~h}$ of incubation for $30 \mathrm{~min}$ on a horizontal shaker and filtered through ash-free cellulose filters. Lower extractant volumes in tropical and other P-poor soils were used to reach higher $\mathrm{P}_{\mathrm{i}}$ concentrations in the bicarbonate extracts for better quantification.

Following this, isobutanol fractionation of the bicarbonate extracts was performed, separating $\mathrm{P}_{\mathrm{i}}$ (into the organic phase) from $\mathrm{P}_{\mathrm{o}}$ (into the acidic aqueous phase) allowing for the measurement of the kinetics and specific activity of the $\mathrm{P}_{\mathrm{i}}$ pool without interference from $\mathrm{P}_{\mathrm{o}}$ (Kellogg et al., 2006; Mooshammer et al., 2012). Isobutanol partitioning enables $100 \%$ recovery of $\mathrm{P}_{i}$ with no hydrolysis of $\mathrm{P}_{\mathrm{o}}$ (Jayachandran et al., 1992). For isobutanol fractionation, each $1.5 \mathrm{~mL}$ of the soil extracts, standards and blanks was amended by sequential addition of $1.5 \mathrm{~mL}$ acidified molybdate, $3 \mathrm{~mL}$ deionized water and $3 \mathrm{~mL}$ isobutanol. The acid- 


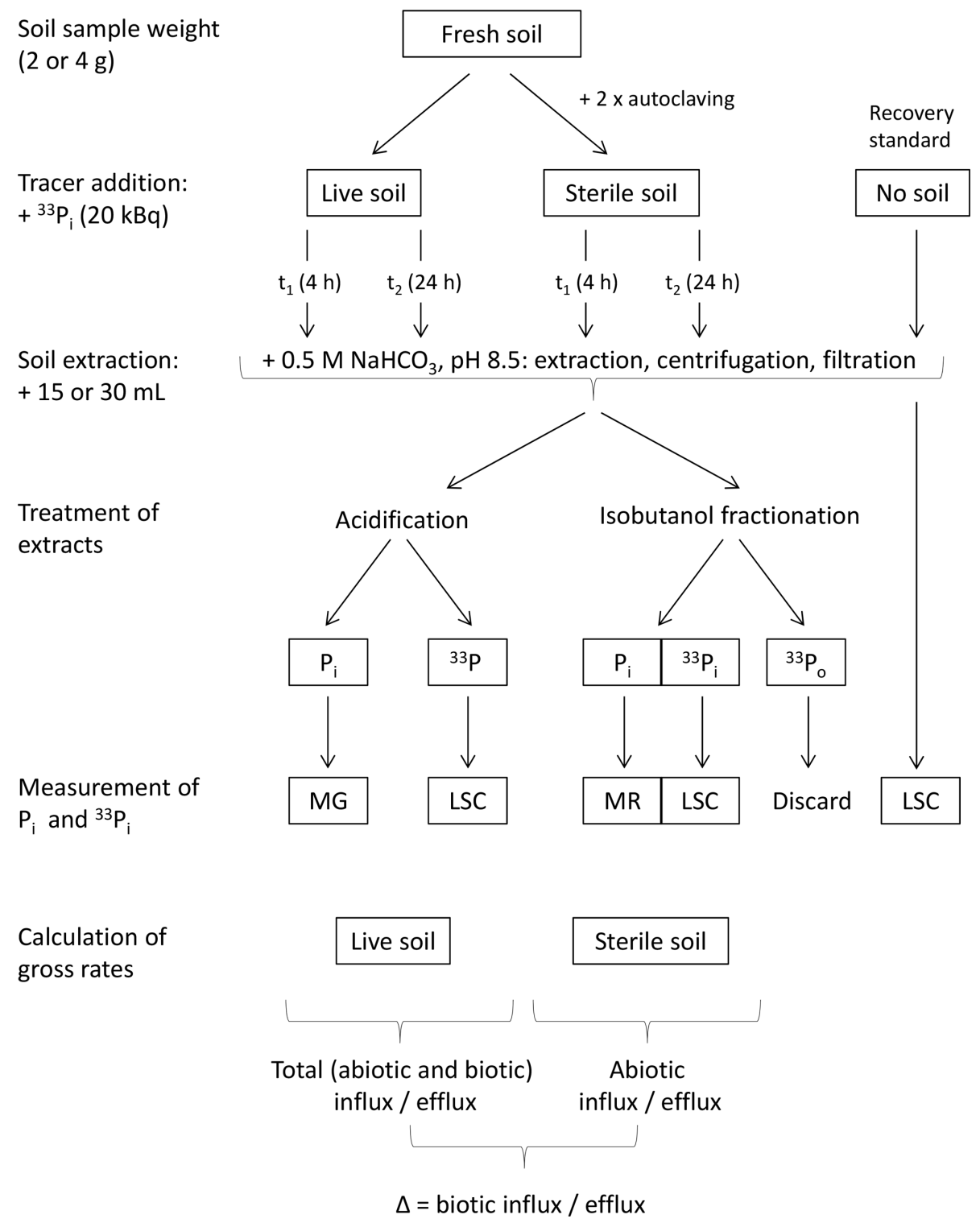

Figure 2. Schematic overview of the final isotope pool dilution (IPD) procedure. MG refers to the malachite green procedure, and MR refers to the Murphy-Riley procedure to measure $\mathrm{P}_{\mathrm{i}}$ concentrations; LSC denotes liquid scintillation counting to measure radioactivity in extracts. Isobutanol fractionation separates dissolved $P_{i}$ from $P_{0}$ and thereby allows for highly specific measurements of concentrations and ${ }^{33} \mathrm{P}$ activities in $\mathrm{P}_{\mathrm{i}}$, without interference from ${ }^{33} \mathrm{P}_{\mathrm{O}}$. Direct acidification of bicarbonate extracts measures dissolved $\mathrm{P}_{\mathrm{i}}$ using malachite green, but LSC quantifies the sum of ${ }^{33} \mathrm{P}_{\mathrm{i}}$ and ${ }^{33} \mathrm{P}_{\mathrm{O}}$; however, the formation of the latter $\left({ }^{33} \mathrm{P}_{\mathrm{O}}\right)$ turned out to be insignificant.

ified molybdate reagent consists of $5 \mathrm{~g}$ ammonium molybdate tetrahydrate $\left(\left(\mathrm{NH}_{4}\right)_{6} \mathrm{Mo}_{7} \mathrm{O}_{24} \cdot 4 \mathrm{H}_{2} \mathrm{O}\right)$ dissolved in $0.1 \mathrm{~L}$ $2.3 \mathrm{M} \mathrm{H}_{2} \mathrm{SO}_{4}$ (stable at room temperature for at least 3 months) and causes strong $\mathrm{CO}_{2}$ outgassing from the bicarbonate extracts. After the addition of all reagents the vials were shaken overhead for $1 \mathrm{~min}$ and then rested for $10 \mathrm{~min}$ for phase separation. For later photometric quantification of $\mathrm{P}_{\mathrm{i}}$ in the isobutanol phase, standards ranging from 320 to $\sim 1 \mu \mathrm{MP}_{\mathrm{i}}(1: 2$ dilution series $)$ and blanks, both of the same matrix as soil extracts (i.e., $0.5 \mathrm{M} \mathrm{NaHCO}_{3}$ ), were prepared and underwent isobutanol fractionation along with the sam- ples. ${ }^{33} \mathrm{P}$ recovery standards were also prepared and processed via the isobutanol fractionation protocol, consisting of the same volume of extractant $(15$ or $30 \mathrm{~mL})$ and ${ }^{33} \mathrm{P}$ tracer activity as added to soils (Fig. 2).

$\mathrm{P}_{\mathrm{i}}$ in the isobutanol phase was quantified using the phosphomolybdate blue color reaction according to Murphy and Riley (1962). Briefly, each $1.5 \mathrm{~mL}$ of the upper organic phase was transferred to vials and amended with $2.1 \mathrm{~mL}$ molybdate free reducing agent, consisting of $1.32 \mathrm{~g}$ ascorbic acid dissolved in $250 \mathrm{~mL}$ antimony potassium tartrate (APT) solution (145.4 mg APT in $0.5 \mathrm{M} \mathrm{H}_{2} \mathrm{SO}_{4}$ ). The APT solution 


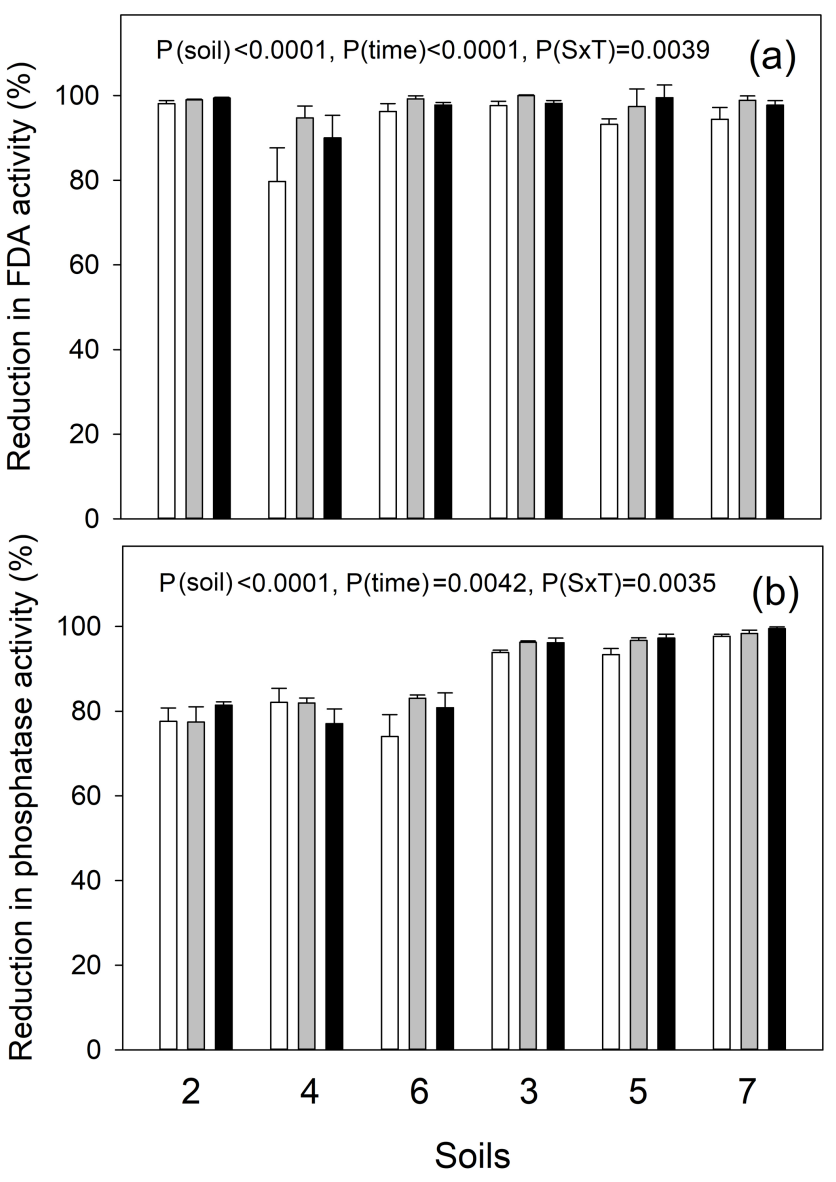

Figure 3. Response of soil enzyme activities to autoclaving: percentage inhibition of (a) fluorescein diacetate (FDA) hydrolysis as a proxy for the inhibition of live, cell-bound microbial enzyme activity and of (b) MUF-phosphomonoesterase activity as a proxy for the inhibition of extracellular enzyme activity. Temperate grassland soils (2, 4 and 6) and tropical forest soils (3, 5 and 7) were tested. A two-way ANOVA was carried out to test for the factors soil, time (1, 24 and $48 \mathrm{~h}$ after second autoclaving cycle, in open, gray and black bars, respectively) and their interaction. $\mathrm{P}$ values are presented.

is stable at room temperature for $>4$ weeks, whereas the molybdate free reducing agent has to be prepared fresh daily. Thereafter, samples were shaken overhead for $1 \mathrm{~min}$ and rested for $20 \mathrm{~min}$ for phase separation and color development. A volume of $250 \mu \mathrm{L}$ of the blue isobutanol phase was then pipetted into a microtiter plate, and the absorbance was read at $725 \mathrm{~nm}$ with a microplate photometer (Tecan Infinite M200, Tecan Austria GmbH, Grödig, Austria).

In parallel to the phosphomolybdate blue reaction of $\mathrm{P}_{\mathrm{i}}$ in the isobutanol phase, $\mathrm{P}_{\mathrm{i}}$ concentrations were also determined directly in acidified bicarbonate extracts using the malachite green approach (D'Angelo et al., 2001). This method is 4-10 times more sensitive than the commonly used phosphomolybdate blue method and was chosen to account for the expectedly low $\mathrm{P}_{\mathrm{i}}$ concentrations of the tropical soils. Standards for calibration of the malachite green method were prepared in $0.5 \mathrm{M} \mathrm{NaHCO}_{3}$, ranging from 50 to $0.039 \mu \mathrm{MP}$. Acidification of bicarbonate extracts and standards (blanks) was performed on $2.5 \mathrm{~mL}$ sample aliquots by adding $250 \mu \mathrm{L} 2.75 \mathrm{M} \mathrm{H}_{2} \mathrm{SO}_{4}$ (Fig. 2). Of the acidified samples and standards, $200 \mu \mathrm{L}$ was pipetted into a microtiter plate, and $40 \mu \mathrm{L}$ of malachite green reagent A was added and incubated for $10 \mathrm{~min}$. Then, $40 \mu \mathrm{L}$ of reagent $B$ was added, and the absorbance was read after $45 \mathrm{~min}$ at $610 \mathrm{~nm}$ with a microplate reader. Reagent A was prepared by pipetting $50 \mathrm{~mL}$ deionized water into an amber $0.1 \mathrm{~L}$ glass bottle, adding $16.8 \mathrm{~mL}$ concentrated $\mathrm{H}_{2} \mathrm{SO}_{4}$, and stirring and dissolving $1.76 \mathrm{~g}$ ammonium heptamolybdate tetrahydrate $\left(\left(\mathrm{NH}_{4}\right)_{6} \mathrm{Mo}_{7} \mathrm{O}_{24} \cdot 4 \mathrm{H}_{2} \mathrm{O}\right)$. Reagent $\mathrm{B}$ was prepared by heating $0.25 \mathrm{~L}$ of distilled $\mathrm{H}_{2} \mathrm{O}$ to $80^{\circ} \mathrm{C}$ in an amber $0.5 \mathrm{~L}$ glass bottle, dissolving $0.875 \mathrm{~g}$ PVA (polyvinyl alcohol, $\mathrm{MW}=72000 \mathrm{~g} \mathrm{~mol}^{-1}$ ) whilst continuously stirring, cooling to room temperature and finally dissolving $87 \mathrm{mg}$ malachite green oxalate in this solution. Both reagents are stable for $>6$ months at room temperature.

Radioactivity $\left({ }^{33} \mathrm{P}\right.$ activity) was measured in $0.25 \mathrm{~mL}$ aliquots of acidified bicarbonate extracts and in $0.4 \mathrm{~mL}$ aliquots of the isobutanol phase, after the addition of each $4 \mathrm{~mL}$ scintillation cocktail (Ultima Gold, Perkin Elmer), by liquid scintillation counting (Tri-Carb 1600 TR, Packard, Perkin Elmer) (Fig. 2).

\subsection{Experiments}

i. Time kinetics: high-resolution time kinetics of tracer and tracee dynamics $\left({ }^{33} \mathrm{P}_{\mathrm{i}},{ }^{31} \mathrm{P}_{\mathrm{i}}\right)$ were measured in two soils (temperate grassland, soil 4; tropical forest, soil 3; Table 2). After tracer addition to live and sterile soils in triplicates, IPD assays were stopped by extraction with $0.5 \mathrm{MNaHCO}_{3}$ after $0,1,2,4,8,24$ and $48 \mathrm{~h}$. Time point 0 was assessed by adding the tracer solution and immediately extracting the soils with $0.5 \mathrm{M} \mathrm{NaHCO}_{3}$.

ii. Microbial ${ }^{33} \mathrm{P}$ immobilization: the procedure outlined in Sect. 2.3 can be combined with the direct determination of microbial $\mathrm{P}$ by extraction with liquid chloroform-enriched salt solutions (Setia et al., 2012). Here, we tested a sequential extraction-liquid chloroform extraction (sECE) procedure. After $24 \mathrm{~h}$ of soil incubation in experiment (i), soil samples $(2 \mathrm{~g}$ fresh weight) were first extracted with 15 (soil 4) or 30 (soil 3) $\mathrm{mL} 0.5 \mathrm{M} \mathrm{NaHCO}_{3}$ for $30 \mathrm{~min}$ and centrifuged for $15 \mathrm{~min}$ at $10.000 \mathrm{~g}$, before the supernatant was decanted. The soil residue was then re-extracted with 15 (30) $\mathrm{mL} 0.5 \mathrm{M} \mathrm{NaHCO}_{3}$ containing $3 \%(v: v)$ chloroform for $30 \mathrm{~min}$ and finally filtered through ash-free cellulose filters. Volume corrections were applied for extractant absorption by the soil pellet after centrifugation. Volume corrections were calculated as soil wet weight after centrifugation minus fresh weight weighed into each tube in grams, divided by the density of the bi- 
carbonate solution (in $\mathrm{g} \mathrm{mL}^{-1}$ ), providing the carryover of extractant from the first extraction (in $\mathrm{mL}$ ).

iii. Soil effects on tracer dynamics: live and sterile soils $(2 \mathrm{~g}$ aliquots) of all six soils (Table 2) were measured in triplicates for ${ }^{33} \mathrm{P}_{\mathrm{i}}$ activity and $\mathrm{P}_{\mathrm{i}}$ concentrations, and assays were stopped after 0,4 and $24 \mathrm{~h}$. Net immobilization of ${ }^{33} \mathrm{P}$ and gross process rates were calculated for the time interval 4 to $24 \mathrm{~h}$, and relationships between gross and net soil $\mathrm{P}$ processes and soil physicochemical parameters were tested.

\subsection{Calculations of abiotic and biotic net ${ }^{33} \mathbf{P}$ immobilization}

In addition to the measurement of gross rates, abiotic net ${ }^{33} \mathrm{P}$ immobilization (net soil $\mathrm{P}_{\mathrm{i}}$ fixation) and biotic net ${ }^{33} \mathrm{P}$ immobilization (net soil microbial $\mathrm{P}_{\mathrm{i}}$ immobilization) were calculated based on the determination of the recovery of added tracer in soil extracts of live and autoclaved soils (see above) after $0,1,2,4,8,24$ and $48 \mathrm{~h}$. Abiotic immobilization (in \% added tracer) was estimated as $100 \%$ minus the percent ${ }^{33} \mathrm{P}$ recovery in autoclaved soils. Total immobilization was estimated as 100 minus the percent ${ }^{33} \mathrm{P}$ recovery in live soils. $\mathrm{Bi}$ otic immobilization was calculated as the difference between total and abiotic immobilization. These data provide a rapid assessment of the abiotic versus microbial sink strengths for $\mathrm{P}_{\mathrm{i}}$, but do not represent gross rates.

\subsection{Calculations of gross rates of soil $\mathbf{P}$ dynamics}

Calculation of gross IPD rates followed the mass balance equations of Kirkham and Bartholomew (1954), as later applied by others for soil gross P fluxes (Kellogg et al., 2006; Mooshammer et al., 2012). In these gross P-flux studies abiotic processes were not corrected for; therefore, $\mathrm{P}_{\mathrm{i}}$ influx rates represent the sum of biotic (organic $\mathrm{P}$ mineralization) and abiotic (desorption) processes, the latter of which do not play a significant role in decomposing litter that is devoid of soil minerals (Mooshammer et al., 2012). However, to calculate gross $\mathrm{P}_{\mathrm{o}}$ mineralization for soils, gross rates of $\mathrm{P}_{\mathrm{i}}$ desorption have to be corrected for in live soils. In the present study, this abiotic correction was performed by applying IPD calculations for influx (GI - gross influx; Eq. 1) for sterile soils (abiotic influx by $\mathrm{P}_{\mathrm{i}}$ desorption) and live soils (total $\mathrm{P}_{\mathrm{i}}$ influx), and taking the difference as the biotic influx (i.e., gross $\mathrm{P}_{\mathrm{O}}$ mineralization). The same procedure was performed for tracer efflux (GE - gross efflux; Eq. 2), calculating gross immobilization fluxes for live soils (total $\mathrm{P}_{\mathrm{i}}$ efflux) and sterile soils ( $\mathrm{P}_{\mathrm{i}}$ sorption), with the difference providing gross rates of microbial $\mathrm{P}_{\mathrm{i}}$ immobilization. Both abiotic corrections are based on the assumption that abiotic sorption/desorption processes are not affected by autoclaving, i.e., that these pro- cesses act similarly in sterile and in live soils.

Gross influx is calculated as

$\mathrm{GI}=\frac{C_{t_{2}}-C_{t_{1}}}{t_{2}-t_{1}} \times \frac{\ln \left(\frac{\mathrm{SA}_{t_{1}}}{\mathrm{SA}_{t_{2}}}\right)}{\ln \left(\frac{C_{t_{2}}}{C_{t_{1}}}\right)}$

and gross efflux is calculated as

$\mathrm{GE}=\frac{C_{t_{1}}-C_{t_{2}}}{t_{2}-t_{1}} \times\left(1+\frac{\ln \left(\frac{\mathrm{SA}_{t_{2}}}{\mathrm{SA}_{t_{1}}}\right)}{\ln \left(\frac{C_{t_{2}}}{C_{t_{1}}}\right)}\right)$,

where $t_{1}$ and $t_{2}$ represent incubation time (4 and $24 \mathrm{~h}$; in days), $C$ represents the soil $\mathrm{P}_{\mathrm{i}}$ concentration (in $\mu \mathrm{g} \mathrm{P}_{\mathrm{i}} \mathrm{g}^{-1}$ soil dw), SA represents the specific activity (in $\mathrm{Bq} \mu \mathrm{g}^{-1} \mathrm{P}_{\mathrm{i}}$ ) and $\mathrm{LN}$ is the natural logarithm. Thus, gross rates are in micrograms of soil inorganic phosphorus per gram soil dry weight per day $\left(\mu \mathrm{g} \mathrm{P}_{\mathrm{i}} \mathrm{g}^{-1}\right.$ soil $\left.\mathrm{dw} \mathrm{d}^{-1}\right)$. Net organic $\mathrm{P}$ mineralization rates can easily be derived by subtracting gross microbial $\mathrm{P}_{\mathrm{i}}$ uptake from gross $\mathrm{P}_{\mathrm{o}}$ mineralization rates.

Due to the relatively rapid decline in ${ }^{33} \mathrm{P}$ activity by radioactive decay, all data were decay-corrected back to the start of each experiment, i.e., the time point of tracer addition to the soil. This was done according to Eq. (3):

$N_{t_{0}}=\frac{N_{\mathrm{t}}}{e^{-\lambda t}}$

where $N_{t_{0}}$ is the decay-corrected ${ }^{33} \mathrm{P}$ activity in a sample (in $\mathrm{Bq}), N_{t}$ is the measured ${ }^{33} \mathrm{P}$ activity at time of liquid scintillation counting, $t$ is time (in days) elapsed between tracer addition and ${ }^{33} \mathrm{P}$ activity measurement, $e=2.71828$ and $\lambda$ is the decay constant of ${ }^{33} \mathrm{P}(0.0273539)$.

\subsection{Statistics}

Regressions were performed in Sigmaplot 13.0 (Systat Software, Inc.) and group differences were tested using one-way and two-way ANOVA tests followed by a Tukey HSD test in Statgraphics Centurion XVIII (Statpoint Technologies, Inc.). Variance homogeneity was tested using a Levene test and if necessary data were log, square root or rank transformed to meet assumptions of homoscedasticity and normal distribution.

\section{Results}

\subsection{Soil characterization}

Temperate grassland soils had a $\mathrm{pH}$ between 6.3 and 6.8, with a silt loam to sandy loam texture (Table 2). Soil organic $\mathrm{C}$ contents ranged between 48 and $127 \mathrm{mg} \mathrm{C} \mathrm{g}^{-1}$ soil dw, soil $\mathrm{N}$ from 2.3 to $5.0 \mathrm{mg} \mathrm{N} \mathrm{g}^{-1}$ soil dw and soil total $\mathrm{P}$ from 0.44 to $0.82 \mathrm{mg} \mathrm{P} \mathrm{g}^{-1}$ soil dw. Tropical forest soils 
had a $\mathrm{pH}$ between 4.1 and 4.2 , and soil texture varied between silt, silty loam and sandy loam. Soil organic $\mathrm{C}$ contents were lower at 26 to $31 \mathrm{mg} \mathrm{Cg}^{-1}$ soil dw, soil $\mathrm{N}$ ranged from 2.2 to $2.6 \mathrm{mg} \mathrm{N} \mathrm{g}^{-1}$ soil dw, and soil total $\mathrm{P}$ ranged from 0.09 to $0.17 \mathrm{mg} \mathrm{P} \mathrm{g}^{-1}$ soil dw. Organic $\mathrm{P}$ comprised a larger fraction of total $\mathrm{P}$ in tropical forest soils $(64 \%-76 \%)$ than in temperate grassland soils $(22 \%-57 \%)$. Extractable soil $\mathrm{P}_{\mathrm{i}}$ was higher in temperate grasslands $\left(4.2-13.1 \mu \mathrm{g} \mathrm{P}^{-1}\right.$ soil dw) compared with tropical forest soils $\left(0.07-0.13 \mu \mathrm{g} \mathrm{P} \mathrm{g}^{-1}\right.$ soil dw). Acid phosphomonoesterase activities of tropical for-

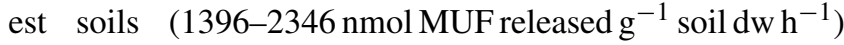
markedly exceeded those in temperate grasslands (233$256 \mathrm{nmol} \mathrm{MUF} \mathrm{released} \mathrm{g}^{-1}$ soil $\mathrm{dw}^{-1}$ ).

\subsection{Abiotic controls: soil sterilization efficiency}

A separation of biotic and abiotic processes is based on the comparison of gross rates using the IPD assay in live versus autoclaved soils, where the latter should not exhibit any microbial activity (no FDA hydrolysis activity) and no extracellular enzyme activities (no MUF-phosphatase activity), in order to serve as abiotic controls. An incomplete inhibition of extracellular phosphatase activities would lead to an underestimation of biological processes and, therefore, of gross $P_{o}$ mineralization. Our results show that two consecutive treatments of the soils by autoclaving, with a $48 \mathrm{~h}$ incubation in between, effectively reduced microbial metabolic activity as shown by the reduction in soil FDA hydrolysis by $90 \%$ in soil 4 and by $97 \%-99 \%$ in all other soils (Fig. 3). Autoclaved soils did not show any increase in soil microbial activity during the $2 \mathrm{~d}$ of incubation. On the contrary, the inhibition of FDA hydrolysis even increased from $1 \mathrm{~h}$ (all soil average: $94 \%$ ) towards 24 and $48 \mathrm{~h}$ after sterilization (average: $97 \%-99 \%$ ). The inhibition of extracellular acid phosphatase activity was almost complete in tropical soils $(95 \%-$ $97 \%$ ) and strongly reduced in temperate soils (79\%-80\%). Similar to FDA hydrolysis, the extent of inhibition of phosphatase activity increased from day 0 (average: $86 \%$ ) to day 1 and 2 (average: $88 \%-89 \%$, Fig. 3). However, autoclaving increased available $P_{i} 1.86 \pm 0.32$-fold (mean $\pm 1 S D$ ) in temperate soils and $1.65 \pm 0.36$-fold in the tropical soils (Fig. S1).

\subsection{Comparison of isobutanol fractionation and direct measurements of $P_{i}$ and ${ }^{33} P$ activity}

Soil $\mathrm{P}_{\mathrm{i}}$ concentrations measured using the malachite green method directly in acidified bicarbonate extracts were compared to those measured after isobutanol fractionation by phosphomolybdate blue reaction, including both live and sterile soils. Both approaches yielded similar soil $\mathrm{P}_{\mathrm{i}}$ concentrations, and the relationship showed no bias (slope $=$ $0.979 \pm 0.033$, mean $\pm 1 \mathrm{SE}$ ), with a coefficient of determination of 0.92 (Fig. 4b). The malachite green method is much more sensitive and therefore produced more reliable results
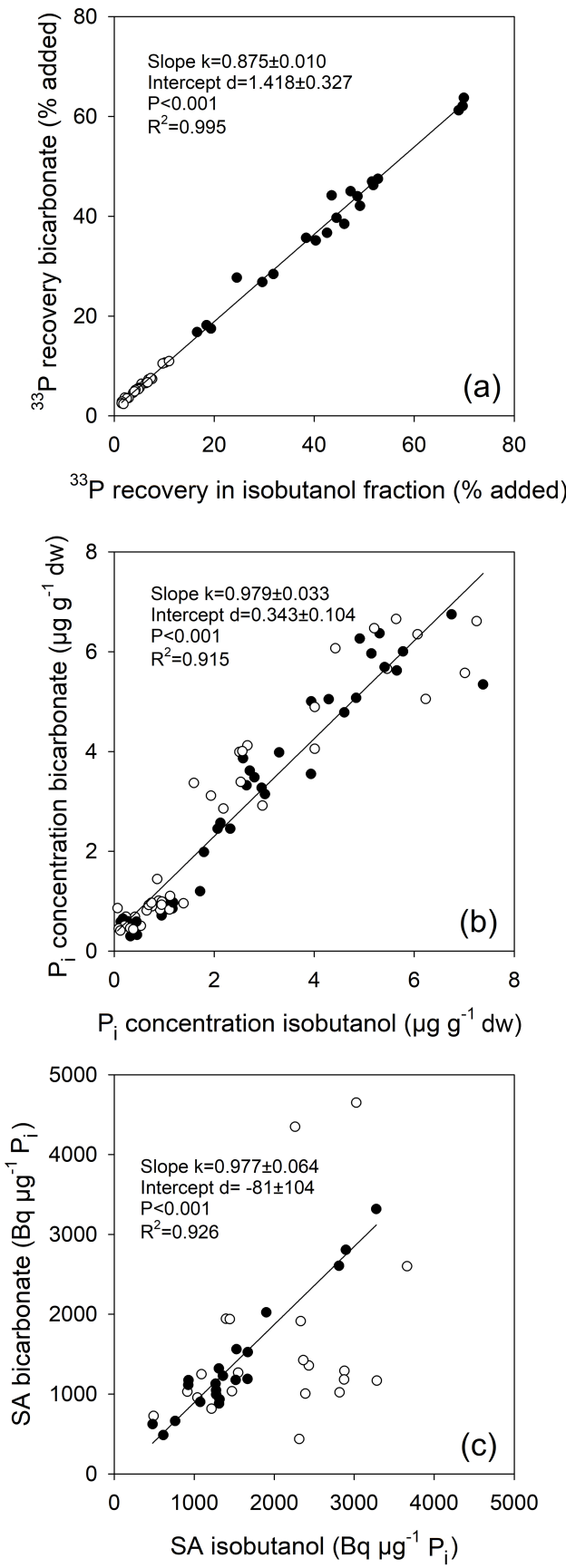

Figure 4. Relationship between (a) ${ }^{33} \mathrm{P}$ recoveries as measured directly in acidified bicarbonate extracts and after isobutanol fractionation, relative to the added tracer amount, and between (b) $\mathrm{P}_{\mathrm{i}}$ concentrations measured using the malachite green method in acidified bicarbonate extracts and after isobutanol fractionation following the phosphomolybdate blue approach. (c) Comparison of specific activities (SA) of $\mathrm{P}_{\mathrm{i}}$ measured in acidified bicarbonate extracts and after isobutanol fractionation. Regression in (c) is only for temperate grassland soils (closed circles); for tropical forest soils (open circles), $\mathrm{P}_{\mathrm{i}}$ concentrations were close to the detection limit of the phosphomolybdate method, impairing calculations of SA for isobutanol fractionation. Linear regressions are given (slopes and intercepts $\pm 1 \mathrm{SD})$. 
for the low-P soils from the three tropical forests. Moreover, the relationship between ${ }^{33} \mathrm{P}$ recoveries by isobutanol fractionation and by direct measurements in acidified bicarbonate extracts had a slope less than 1 (slope $=0.875 \pm 0.010$; Fig. 4a), indicating no significant formation of ${ }^{33} \mathrm{P}_{\mathrm{o}}$ during soil incubations. We also found no ${ }^{33} \mathrm{P}_{\mathrm{o}}$ formation in other soils using the same measurement protocols, e.g., from the Jena biodiversity experiment ( 82 plots of temperate grassland varying in soil texture and plant biodiversity, slope $=$ $0.891 \pm 0.017)$ and from French Guiana (24 soils from two primary forest regions, with soils sampled across topographic gradients, slope $=1.043 \pm 0.020$ ) (same regression types as in Fig. 3a; data not shown). The specific activities of $\mathrm{P}_{\mathrm{i}}$ were indistinguishable between both approaches for temperate soils (slope $=0.977 \pm 0.064, R^{2}=0.93, P<0.0001$; Fig. 4c) but varied strongly for the tropical soils, where soil $P_{i}$ measurements in the isobutanol fraction were at or below the limit of detection of the phosphomolybdate blue method. Specific activities of $P_{i}$ were initially higher in live than in sterile soils (Fig. 4c). This was caused by the addition of the same amount of radiotracer to both, sterile and live soils, but autoclaving caused a flush of $P_{i}$ from lysed soil microbes, which effectively lowered the specific activities of $P_{i}$ in sterile soils.

\subsection{Sensitivity of the IPD assay}

The sensitivity of this assay is greatly improved relative to traditional methods by using a combination of bicarbonate extractions and malachite green $\mathrm{P}_{\mathrm{i}}$ measurements. The detection limit of the IPD approach was $0.12 \mu \mathrm{g} \mathrm{g} \mathrm{g}^{-1}$ soil $\mathrm{dw} \mathrm{d}^{-1}$, based on 3 times the standard deviation of gross $P_{o}$ mineralization, measured for the three tropical soils (each measured in triplicate), and was, therefore, fully suitable across all soil types tested so far. However, the precision suffers from IPD equations that combine uncertainties from four measurements, two $\mathrm{P}_{\mathrm{i}}$ concentrations and two radioactivity measurements for the two time points in live as well sterile soils. The coefficients of variation (CV) ranged between $1.0 \%$ and $22.1 \%$ (average $10.0 \%$ ) for $\mathrm{P}_{\mathrm{i}}$ concentration across temperate and tropical soils, and between $1.5 \%$ and $22.1 \%$ (average $9.6 \%$ ) for SA, the two major input variables into the IPD equation. CVs increased towards lower $P_{i}$ concentrations and higher $\mathrm{SA}$ values, i.e., closer to the detection limit of the malachite green method. The CVs might be reduced by working with larger soil aliquots (increase from 2 to 5 or $10 \mathrm{~g}$ soil fresh weight) and by duplicate measurements of all samples. Purely methodological CVs were lower, at about $2.5 \%$ and $0.9 \%$ for $\mathrm{P}_{\mathrm{i}}$ measurements using malachite green in the range from 3 to 12 and 12 to $120 \mu \mathrm{M}$, respectively, and $0.8 \%$ for liquid scintillation counting. Therefore, much of the shown variability derived from differences between biological soil replicates. However, the variability found here compares well with $\mathrm{CV}$ s published for soil $\mathrm{P}_{\mathrm{i}}$ concentrations of 2\%-10\% (Bünemann et al., 2007) and 20\%-25\% (Büne- mann et al., 2012), and CVs for measured $E$ values that are calculated from $\mathrm{P}_{\mathrm{i}}$ concentrations and ${ }^{33} \mathrm{P}$ recoveries analogous to $S A$ values ranging between $6 \%$ and $16 \%$ (Bünemann et al., 2007), $8 \%$ and $19 \%$ (Bünemann et al., 2012) and $9 \%$ and $10 \%$ (Randriamanantsoa et al., 2015) across a range of cultivated and non-cultivated soils from temperate to tropical regions. These variations naturally propagate into higher errors in the measured rates of soil $\mathrm{P}$ cycling and increase the limit of detection and the limit of quantification of the various methods.

\subsection{Time kinetics}

During the first hour of the incubation, we found a rapid drop in ${ }^{33} \mathrm{P}$ recovery and in the SA of $\mathrm{P}_{\mathrm{i}}$ (Fig. 4), while soil $P_{i}$ concentrations increased slightly (Fig. S1). Thereafter, a dynamic equilibrium between added ${ }^{33} \mathrm{P}$ tracer and the soil $P_{i}$ pool was reached and concentrations of extractable $P_{i}$ remained constant. A plot of $\ln \left({ }^{33} \mathrm{P}\right.$ recovery $)$ versus time for both live and sterile soils showed that the consumption of ${ }^{33} \mathrm{P}$ occurred linearly between 4 and $48 \mathrm{~h}$ in the temperate soil and between 2 and $24 \mathrm{~h}$ in the tropical soil (Fig. 5). Similarly, the plot of $\ln \left(\mathrm{SA}\right.$ of $\left.\mathrm{P}_{\mathrm{i}}\right)$ versus time showed a linear relationship from 4 to $48 \mathrm{~h}$ in the temperate soil and for 2 to $48 \mathrm{~h}$ in the tropical soil, particularly in live soils (Fig. 5), with constant dilution of the isotopic signature of the pool over time. The regressions became insignificant in the sterile tropical soil, as ${ }^{33} \mathrm{P}$ recovery and SA declined more slowly. The data clearly show that abiotic ${ }^{33} \mathrm{P}$ processes (i.e., decreases in ${ }^{33} \mathrm{P}$ recovery and SA of $\mathrm{P}_{\mathrm{i}}$ over time in sterile soils) occurred, particularly in the temperate soil, and that this occurred over a prolonged period of time. More importantly, the dynamics of the abiotic ${ }^{33} \mathrm{P}$ processes changed over time: rapid abiotic immobilization during the initial $0-4 \mathrm{~h}$ was followed by a period of slower but linear tracer immobilization.

\subsection{Net ${ }^{33} \mathrm{P}$ immobilization by abiotic and biotic processes}

Abiotic net ${ }^{33} \mathrm{P}$ immobilization (net soil $\mathrm{P}$ fixation) increased markedly from 0 to $48 \mathrm{~h}$ in the grassland soil $(17 \%$ to $58 \%$ of added tracer), while it reached $83 \%$ almost instantaneously in tropical soil and further increased to $90 \%$ after $48 \mathrm{~h}$ (Fig. 6a). Similar patterns were found across all six soils, with significantly higher abiotic net immobilization in tropical than in temperate soils, increasing in both with time from 0 to 4 and $24 \mathrm{~h}$ (Fig. 6c). Biotic (microbial) net ${ }^{33} \mathrm{P}$ immobilization ranged from $3 \%$ to $8 \%$ in the tropical soil and 8 to $17 \%$ in the temperate soil in the time kinetics experiment, with a significant increase in the temperate but not in the tropical soil (Fig. 6b). Similarly, biotic net ${ }^{33} \mathrm{P}$ immobilization was low but increased with time in all three tropical soils (3\% to $6 \%$ ), while it was significantly higher in temperate soils but increased (soil 6) or decreased (soil 2 and 4) with time (Fig. 6d). Microbial immobilization was very fast, 

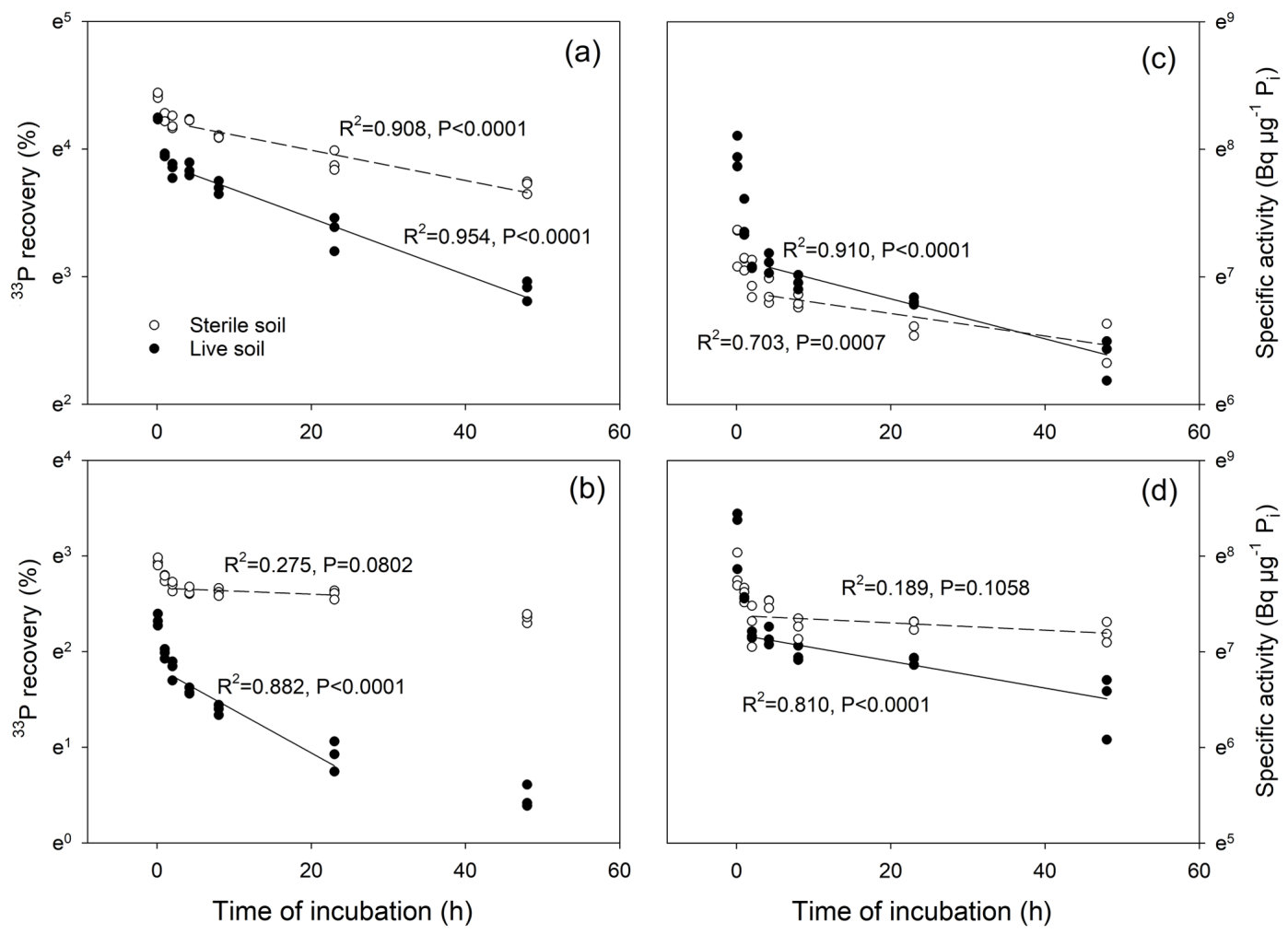

Figure 5. Test for linearity of change in ${ }^{33} \mathrm{P}$ recoveries $(\mathbf{a}, \mathbf{b})$ and in specific activities of $\mathrm{P}_{\mathrm{i}}(\mathbf{c}$, $\mathbf{d})$ over time, for a temperate grassland soil $(\mathbf{a}, \mathbf{c})$ and a tropical forest soil $(\mathbf{b}, \mathbf{d})$. Data presented are for ${ }^{33} \mathrm{P}$ measured directly in bicarbonate extracts of live soils (closed circles) and sterile soils (open circles), and are shown in a logarithmic manner (LN) on the $y$ axes. Regression lines follow exponential decay which in this linear-LN plot appears as a straight line; dashed lines represent sterile soils, and solid lines represent live soils. Regressions were calculated for the time intervals from 2 to $24 \mathrm{~h}$ (tropical soil) and from 4 to $48 \mathrm{~h}$ (temperate soil).

with almost instantaneous ${ }^{33} \mathrm{P}$ uptake by microbes (sampling at $0 \mathrm{~h}$ ), ranging between $3 \%$ (tropical soils) and $15 \%-38 \%$ (temperate soils). Given the strong changes in both abiotic and biotic net ${ }^{33} \mathrm{P}$ immobilization, we suggest that it is best to measure them after $24 \mathrm{~h}$ (up to $48 \mathrm{~h}$ ).

Sequential extraction-liquid chloroform-extraction (sECE) was applied to directly follow net ${ }^{33} \mathrm{P}$ uptake by microbes, whereas biotic net ${ }^{33} \mathrm{P}$ immobilization was estimated indirectly as the difference in net ${ }^{33} \mathrm{P}$ immobilization by live and sterile soils. In the two measured soils, sECE estimates of microbial net ${ }^{33} \mathrm{P}$ uptake were higher than the microbial net ${ }^{33} \mathrm{P}$ immobilization estimates (temperate soil was $24.6 \%$ versus $16.0 \%$, and tropical soil was $16.8 \%$ versus $7.5 \%$, for direct and indirect estimates, respectively). This indicates incomplete extraction of exchangeable $\mathrm{P}_{\mathrm{i}}$ prior to microbial lysis with chloroform and re-extraction.

\section{$3.7{ }^{33} \mathrm{P}$ pool dilution rates of abiotic and biotic processes}

We calculated gross $P_{i}$ influx and efflux rates for live and sterile soils. The calculated rates of sterile soils provide estimates of gross rates of soil $\mathrm{P}_{\mathrm{i}}$ sorption and desorption, and the difference between live and sterile soils give the bi- otic influx (gross $\mathrm{P}_{\mathrm{o}}$ mineralization) and efflux (gross microbial $P_{i}$ uptake). Gross $P_{o}$ mineralization significantly differed between soils, with two out of three temperate soils ( 0.48 to $2.03 \mu \mathrm{g} \mathrm{g} \mathrm{g}^{-1} \mathrm{dw} \mathrm{d}^{-1}$ ) exhibiting higher rates than two out of three tropical soils $\left(0.08\right.$ to $\left.0.15 \mu \mathrm{g} \mathrm{P} \mathrm{g}^{-1} \mathrm{dw} \mathrm{d}^{-1}\right)$ (Fig. 7a). Gross rates of $P_{i}$ sorption in temperate soils (2.06 to $6.14 \mu \mathrm{g} \mathrm{g} \mathrm{g}^{-1} \mathrm{dw} \mathrm{d}^{-1}$ ) were higher than in tropical soils ( 0.15 to $0.32 \mu \mathrm{g} \mathrm{g} \mathrm{g}^{-1} \mathrm{dw} \mathrm{d}^{-1}$ ), and a similar trend was found for gross rates of microbial $\mathrm{P}_{\mathrm{i}}$ uptake (temperate soils: 0.44 to $1.13 \mu \mathrm{g} \mathrm{Pg}^{-1} \mathrm{dw} \mathrm{d}^{-1}$; tropical soils: 0.05 to $0.12 \mu \mathrm{g} \mathrm{g}^{-1} \mathrm{dw} \mathrm{d}^{-1}$; Fig. $7 \mathrm{~b}$ ). Gross rates of soil $\mathrm{P}_{\mathrm{i}}$ desorption were significantly higher in temperate soils $\left(1.44-3.63 \mu \mathrm{g} \mathrm{P} \mathrm{g}^{-1} \mathrm{dw} \mathrm{d}^{-1}\right)$ than in tropical soils $(0.04$ $0.14 \mu \mathrm{g} \mathrm{Pg}^{-1} \mathrm{~d}^{-1}$, Fig. 7a). The relative contribution of $P_{o}$ mineralization to total $P_{i}$ release into the soil $P_{i}$ pool ranged between $25.0 \%$ and $73.8 \%$, with two tropical P-poor soils showing the highest contributions (Fig. 7c). Contributions of biological processes to gross $P_{i}$ immobilization did not differ between soils (ranged from $11.5 \%$ to $34.9 \%$ ). 

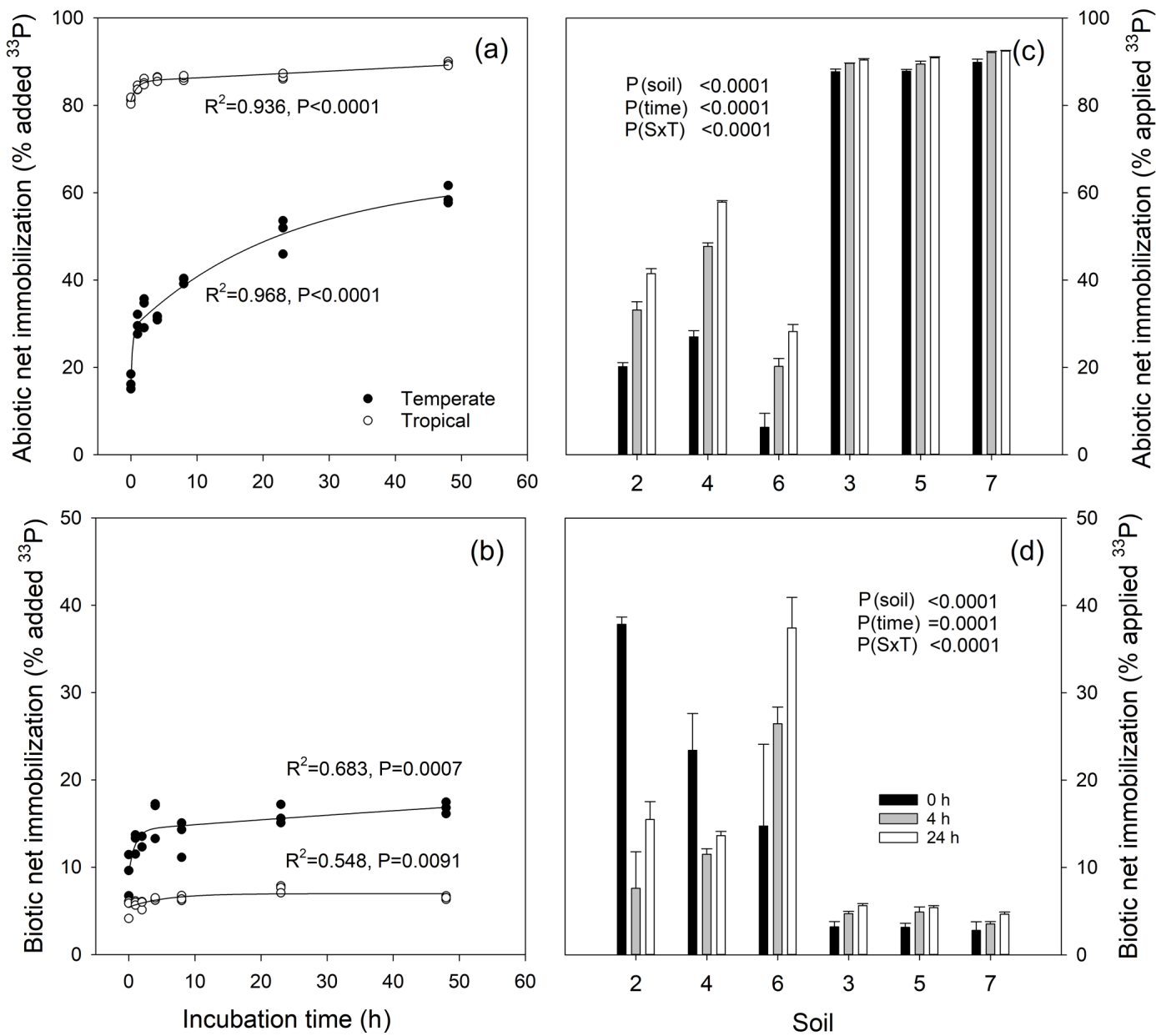

Figure 6. Net immobilization rates of ${ }^{33} \mathrm{P}_{\mathrm{i}}$ by abiotic processes (sorption; a, c) measured in sterile soils and biotic processes (microbial uptake; b, d) measured in live soils of a temperate grassland (soil 4) and a tropical forest (soil 3) after 0, 1, 2, 4, 8, 24 and 48 h (a, b) and for six soils measured after 0,4 and $24 \mathrm{~h}(\mathbf{c}, \mathbf{d})$. Temperate grassland soils $(2,4$ and 6$)$ and tropical forest soils $(3,5$ and 7$)$ were investigated in (c) and (d). Curvilinear regressions following the function "exponential rise to maximum" were performed on the data in (a, b). Statistical analyses of data in $(\mathbf{c}, \mathbf{d})$ were undertaken using a two-way ANOVA for the factors soil and time ( 0,4 and $24 \mathrm{~h}$ after tracer addition), and the interaction between factors.

\subsection{Physicochemical and biological controls on soil $\mathbf{P}_{\mathbf{i}}$ processes}

Gross $\mathrm{P}_{\mathrm{o}}$ mineralization was strongly positively correlated with total soil $\mathrm{P}\left(R^{2}=0.87, P<0.01 ;\right.$ Fig. $\left.8 \mathrm{a}\right)$ and with total as well as extractable soil $\mathrm{P}_{\mathrm{i}}$ concentration $\left(R^{2}>0.83\right.$, $P<0.05$; Fig. 8b), but not with soil organic $\mathrm{P}$ or its contribution to soil total $\mathrm{P}$, nor with soil organic $\mathrm{C}$, soil texture or soil acid phosphatase activity (Table $\mathrm{S} 1$ ). Gross abiotic $\mathrm{P}_{\mathrm{i}}$ release rates via desorption and dissolution were strongly positively related to total soil $\mathrm{P}$ and bicarbonate soil $\mathrm{P}_{\mathrm{i}}\left(R^{2}=0.97\right.$ and 0.98 , respectively, both $P<0.001$; Fig. $8 \mathrm{c}$ and Table S1), but not to other parameters such as soil $\mathrm{pH}$, soil texture and soil organic $\mathrm{C}$ content. Gross $\mathrm{P}_{\mathrm{i}}$ sorption rates exceeded gross $\mathrm{P}_{\mathrm{i}}$ desorption rates approximately 2 -fold, but both were strongly related $\left(R^{2}=0.99, P<0.001\right.$; Fig. $\left.8 \mathrm{e}\right)$. Gross $\mathrm{P}_{\mathrm{i}}$ sorption rates were strongly positively related to soil total $\mathrm{P}\left(R^{2}=\right.$
0.96, $P<0.001$; Fig. 8d), soil total $\mathrm{P}_{\mathrm{i}}\left(R^{2}=0.88, P<0.05\right.$; Table S1) and bicarbonate soil $\mathrm{P}_{\mathrm{i}}\left(R^{2}=0.99, P<0.001\right.$; Table $\mathrm{S} 1$ ), but not to soil $\mathrm{pH}$, soil organic $\mathrm{C}$, nor clay content or soil texture. Abiotic net $\mathrm{P}_{\mathrm{i}}$ immobilization was most strongly, negatively related to soil $\mathrm{pH}\left(R^{2}=0.95, P<0.001\right.$; Fig. 81$)$ and weakly, negatively related to soil $\mathrm{P}_{\mathrm{i}}$ sorption $\left(R^{2}=0.59\right.$, $P=0.073$; Fig. 8j). Gross microbial $P_{\mathrm{i}}$ uptake rates were directly proportional to microbial biomass $\mathrm{P}$ measured by $\operatorname{sECE}\left(R^{2}=0.95, P<0.01 ;\right.$ Fig. $\left.8 \mathrm{~g}\right)$, and positively related to net microbial $\mathrm{P}_{\mathrm{i}}$ immobilization $\left(R^{2}=0.85, P<0.01\right.$; Fig. 8i). We found a negative curvilinear relationship between net immobilization rates by sorption and microbes $\left(R^{2}=0.97, P<0.001 ;\right.$ Fig. 8f $)$. 

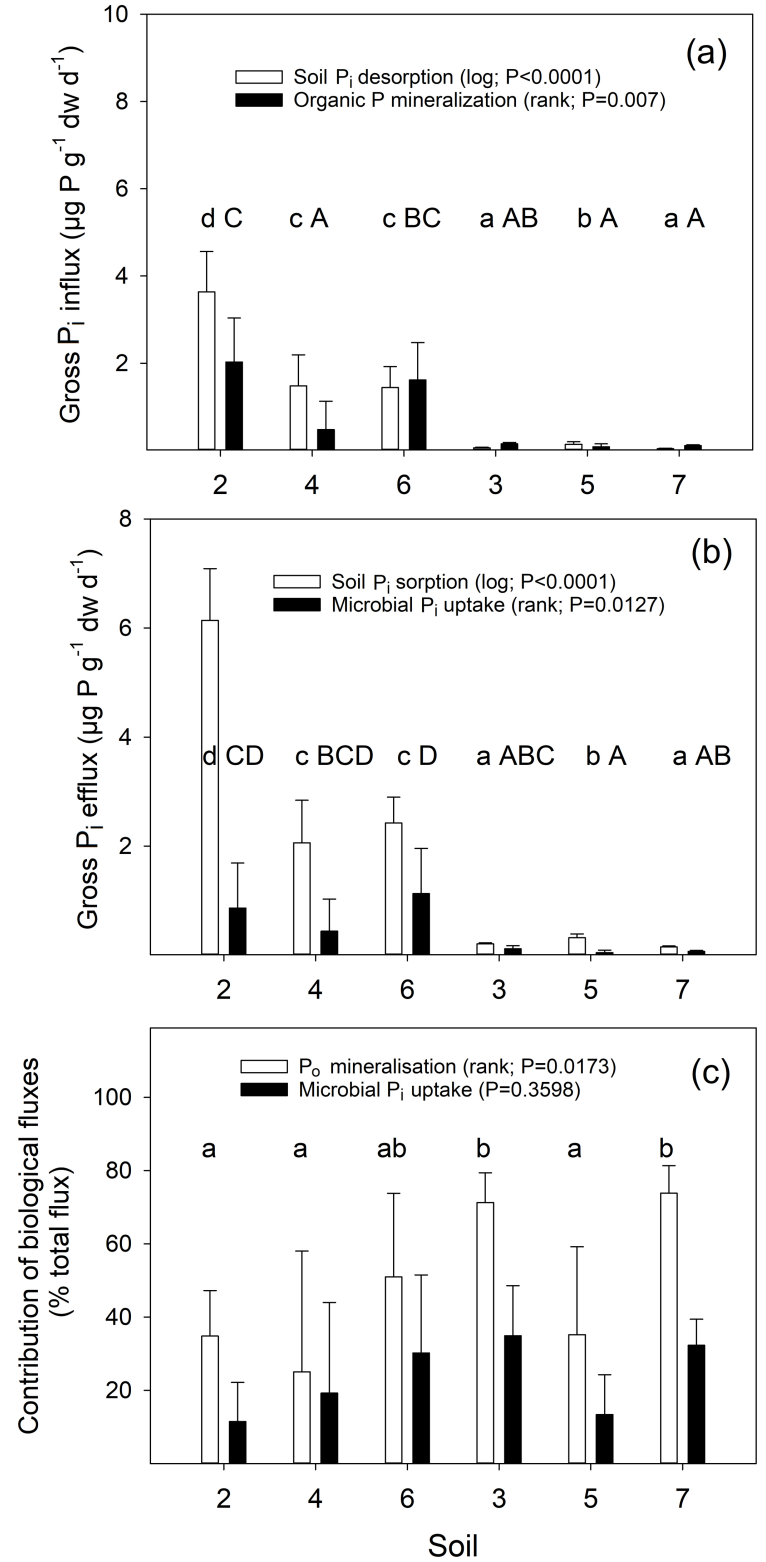

Figure 7. Gross influx rates into the available soil $\mathrm{P}_{\mathrm{i}}$ pool (a) and gross efflux rates from this pool (b) measured by ${ }^{33} \mathrm{P}$ isotope pool dilution for six soils over the time period from 4 to $24 \mathrm{~h}$ and assessed in sterile and live soils. Abiotic and biotic process rates are indicated by open and closed bars, respectively. Temperate grassland soils (2, 4 and 6) and tropical forest soils (3, 5 and 7) were studied. Presented are means \pm 1 SD of triplicate live and sterile soils per time point and soil type. A one-way ANOVA was performed on transformed data, as indicated in parentheses. Different lowercase letters indicate significant differences between soils for abiotic processes (open bars), uppercase letters indicate significant differences between soils for biological processes (black bars).

\section{Discussion}

About a decade ago, Kellogg et al. (2006) compared two IEK techniques with an IPD approach, identifying several biases of the different approaches and making recommendations for further development. The authors recommended the IPD approach with soil extraction using $0.5 \mathrm{M}$ sodium bicarbonate, as it is best suited for any potential soil type. However, this approach is currently underused and has had issues with abiotic controls. IPD methods are state-of-the-art to measure gross processes of soil $\mathrm{N}$ cycling (Murphy et al., 2003), but have rarely been applied to soil P cycling processes (Mooshammer et al., 2012; Di et al., 2000; Kellogg et al., 2006). Here, we present a novel and versatile approach to derive quantitative estimates of soil P-cycling processes that drive soil $\mathrm{P}$ availability in low- to high-P soils. The approach quantifies gross rates of soil $P_{o}$ mineralization and the abiotic release of $P_{i}$ from non-extractable soil $P_{i}$ pools $\left(P_{i}\right.$ desorption and dissolution), both of which cause a gross influx of $P_{i}$ into the soil available $P_{i}$ pool. Furthermore, gross rates of $P_{i}$ immobilization by soil sorption and precipitation and by microbial uptake processes are derived from the same data by calculating the efflux from the soil $\mathrm{P}_{\mathrm{i}}$ pool in sterile soils (abiotic) and in live minus sterile soils (biotic processes), respectively.

In contrast to many earlier IEK assays, the IPD approach presented here is based on real isotope pool dilution theory (Kirkham and Bartholomew, 1954), and not on curvilinear extrapolation of $E$ values (Table 1). Moreover, IEK assays of $\mathrm{P}_{\mathrm{O}}$ mineralization necessitate steady-state conditions (constant $\mathrm{P}_{\mathrm{i}}$ and microbial biomass $\mathrm{P}$ pools, and constant rates of isotope exchange and respiration) to allow for the extrapolation of short-term exchange processes to the full length of the moist soil incubation experiments. IPD approaches can accommodate non-steady-state conditions as caused by flush effects and disturbances (Mooshammer et al., 2017) or as induced by the addition of organic matter. The equations to estimate IPD rates can easily be solved for soils where target pool concentrations increase (net mineralization) or decrease (net immobilization) over time and where microbial biomass P changes (Kirkham and Bartholomew, 1954), and do not necessitate constant pool sizes as has been incorrectly suggested in previous studies (Di et al., 2000; Randhawa et al., 2005).

\subsection{Soil sterilization}

${ }^{33} \mathrm{P}$ IPD experiments in soils differ from the more common ${ }^{15} \mathrm{~N}$ IPD variants for gross $\mathrm{N}$ processes (Murphy et al., 2003), as the persistence of abiotic $\mathrm{P}$ processes over time (Figs. 5, 6) needs to be accounted for via the use of sterile soils. Our data clearly show that the dynamics of abiotic ${ }^{33} \mathrm{P}$ processes change over time. Therefore, the IPD rates in the sterile soils need to be measured over the same time period and under similar environmental conditions as in the live soils. It is 


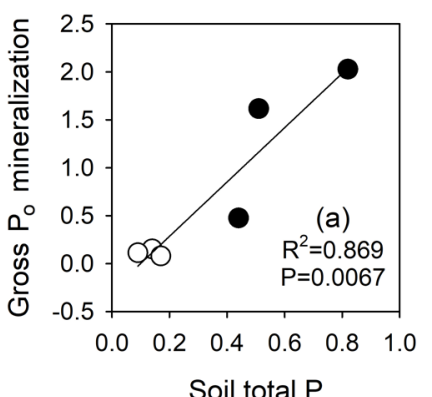

Soil total P
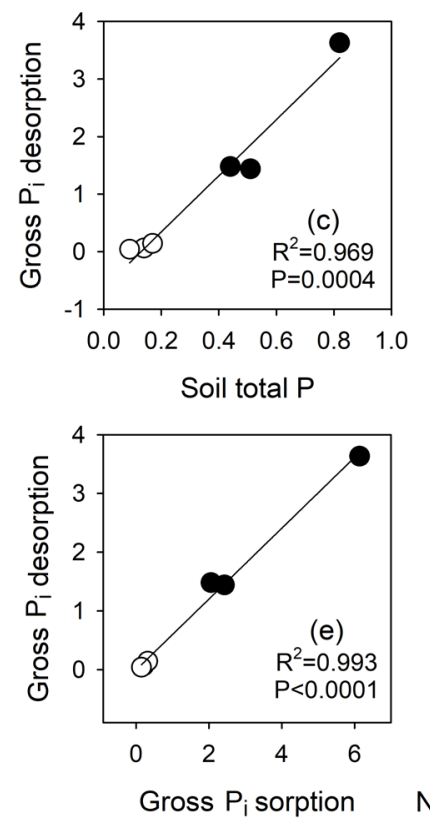

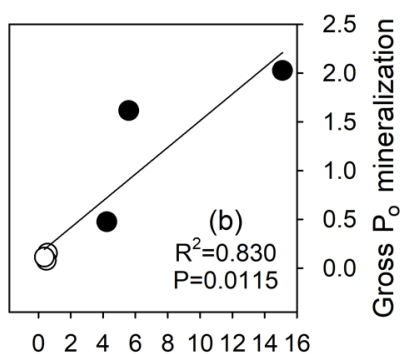

Soil $\mathrm{P}_{\mathrm{i}}$ concentration

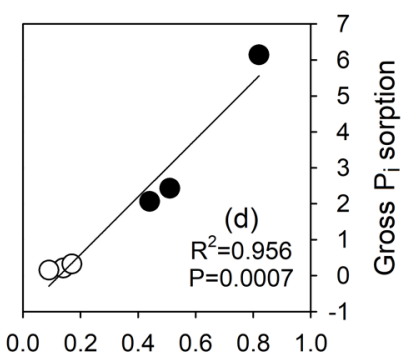

Soil total P

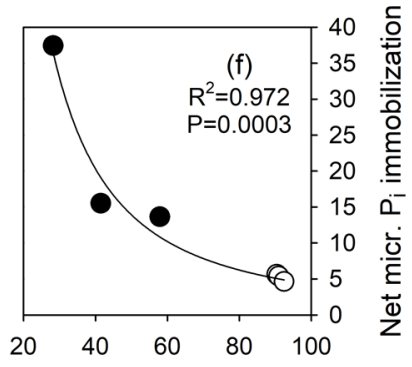

Net abiotic $P_{\mathrm{i}}$ immobilization

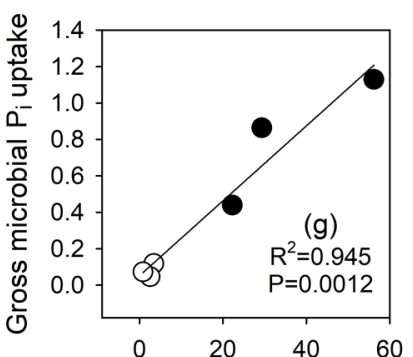

Soil microbial biomass

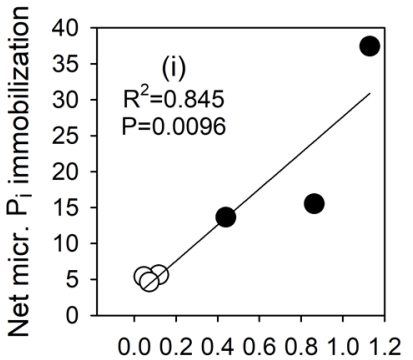

ross microbial $\mathrm{P}_{\mathrm{i}}$ uptake

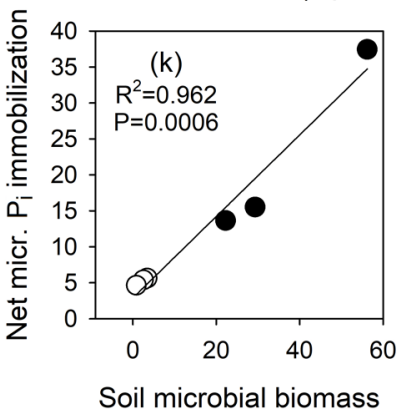

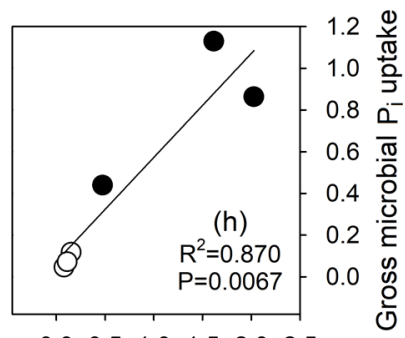

$\begin{array}{llllll}0.0 & 0.5 & 1.0 & 1.5 & 2.0 & 2.5\end{array}$

Gross $P_{\circ}$ mineralization

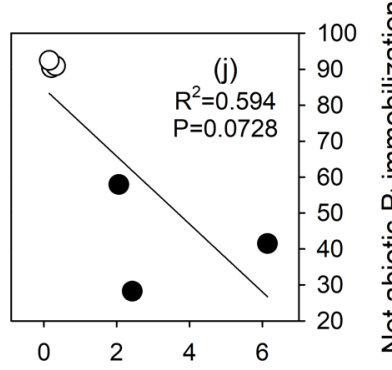

Gross $\mathrm{P}_{\mathrm{i}}$ sorption

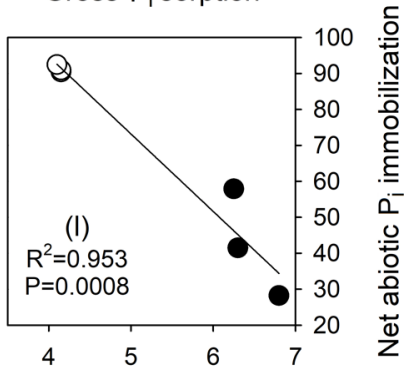

Soil pH

Figure 8. Relationship between selected soil physicochemical parameters, net abiotic and microbial immobilization fluxes, gross $P_{i}$ influx rates by biological processes (gross $\mathrm{P}_{\mathrm{O}}$ mineralization) and abiotic processes (gross $\mathrm{P}_{\mathrm{i}}$ desorption), and gross $\mathrm{P}_{\mathrm{i}}$ efflux rates by biological processes (gross microbial $\mathrm{P}_{\mathrm{i}}$ uptake) and abiotic processes (gross $\mathrm{P}_{\mathrm{i}}$ sorption). Regression lines are for linear or power function fits, and $\mathrm{P}$ and $R^{2}$ values for these are shown. Open circles (०) depict tropical forest soils, and closed circles $(\bullet)$ depict temperate grassland soils. Units are provided in Table 2 for soil physicochemical parameters and phosphomonoesterase, and are the percentage (\%) of added tracer for net processes, and micrograms of phosphorus per gram soil dry weight per day $\left(\mu \mathrm{g} \mathrm{g} \mathrm{g}^{-1}\right.$ soil $\left.\mathrm{dw} \mathrm{d}^{-1}\right)$ for gross process rates.

likely insufficient to extrapolate from short-term (100 min) batch incubations run under very different conditions to correct for abiotic processes in the respective live moist soil incubations over weeks. Bünemann et al. (2007) indicated that batch incubations $(1: 10(w: v)$ soil : water suspensions $)$ have higher water-soluble and isotopically exchangeable $\mathrm{P}_{\mathrm{i}}$ concentrations (measured as extractable $\mathrm{P}_{\mathrm{i}}$ and as $E$ values) and tend to have higher tracer recoveries (measured as $r / R$, i.e., water-soluble ${ }^{33} \mathrm{P}_{\mathrm{i}}$ recovered relative to total ${ }^{33} \mathrm{P}_{\mathrm{i}}$ added) compared with moist soil incubations. Therefore, incubation conditions should also match between live and sterile soils.

We chose autoclaving as the sterilization procedure as other procedures only reduce or eliminate microbial activity (gamma irradiation, azide, mercuric chloride, toluene or chloroform treatment) but do not curtail extracellular enzyme activities (Blankinship et al., 2014; Wolf et al., 1989; Tiwari et al., 1988; Oehl et al., 2001b). Given that $\mathrm{P}_{\mathrm{o}}$ mineraliza- tion is mediated by extracellular phosphatases, previous isotope experiments using short-term batch experiments with or without microbicides or $\gamma$-irradiation did not inhibit phosphatases and, therefore, did not allow for the separation of abiotic and biotic processes of $P_{i}$ release in soils. While the application of phosphatase inhibitors might be another viable option, we are only aware of one study testing this; the application of silver nanoparticles to soils showed a general inhibitory effect on soil enzymes (Shin et al., 2012). Previous tests in our laboratory with two commercial phosphatase inhibitor cocktails (Sigma-Aldrich) at 10-fold the recommended final concentration did not significantly decrease IPD rates in two soils (data not shown), indicating an insufficient inhibition of extracellular phosphatases. However, more rigorous tests of soil enzyme activities with synthetic substrates (e.g., MUF- $\mathrm{P}_{\mathrm{i}}$ ) and of $\mathrm{P}$ mineralization based on ${ }^{33} \mathrm{P}$ IPD using increasing concentrations and different types 
of commercial phosphatase inhibitor cocktails might clarify whether this approach is viable or not. In contrast, autoclaving soils twice was highly efficient in suppressing biological activities, and those soils had no or very low extracellular enzyme activity and no residual microbial metabolic activity. Previous studies have shown (almost) total inhibition of hydrolytic enzyme activities (including phosphomonoesterases) by autoclaving, in a wide range of arable, grassland and forest soils (Serrasolsas et al., 2008; Kedi et al., 2013; Blankinship et al., 2014; Tiwari et al., 1988). Other studies have demonstrated successful killing of bacterial and fungal cells in soils by autoclaving (Carter et al., 2007; Blankinship et al., 2014; Serrasolsas and Khanna, 1995b; Alphei and Scheu, 1993). Most importantly, the final step in $\mathrm{P}_{\mathrm{o}}$ mineralization is catalyzed by phosphomonoesterases, which were fully inactivated by autoclaving in all soils tested so far.

It must be noted that autoclaving could potentially alter the physicochemical properties of soils, thereby affecting abiotic sorption/desorption kinetics. Despite this, in previous studies autoclaving up to two times and steam sterilization did not affect the cation exchange capacity, nor did it impact base saturation, soil surface area, contents of total organic carbon and total nitrogen, and it only slightly affected soil pH (Wolf et al., 1989; Tanaka et al., 2003; Serrasolsas and Khanna, 1995b). Autoclaving might, however, weaken soil aggregates and therefore increase the number of sites accessible for sorption/desorption processes that were previously hidden in aggregates. However, we did not find clear support for or against this in the literature as autoclaving only weakly affected soil aggregate size distribution, causing a $0.5 \%$ to $1 \%$ increase in clay-sized aggregates compared with siltsized aggregates (Berns et al., 2008). In contrast, aggregate stability and aggregation increased upon autoclaving in two other studies (Lotrario et al., 1995; Salonius et al., 1967). The effects of autoclaving on soil aggregation and soil $\mathrm{P}$ dynamics could be tested by measuring P-process rates on intact aggregates $<2 \mathrm{~mm}$ and after destroying them by ultrasonication or grinding. In our study autoclaving caused a pulse of labile $\mathrm{P}$ into the available soil $\mathrm{P}$ pool due to the lysis of microbial biomass (Fig. S1), as has also been demonstrated for $\mathrm{P}$ and $\mathrm{N}$ by Serrasolsas and Khanna (1995a, b). Soil $\mathrm{P}_{\mathrm{i}}$ concentrations increased significantly in the autoclaved soils studied here, but only by an average of 1.86 -fold in the three temperate soils and 1.65-fold in the three tropical forest soils, which was in the range found by others, e.g., 1.3- to 1.6-fold (Skipper and Westermann, 1973) and 1.5- to 1.6-fold (Anderson and Magdoff, 2005), but lower than reported elsewhere, e.g., 2.6- to 11-fold (Serrasolsas and Khanna, 1995a). Autoclaving was also demonstrated to increase the tracer recovery $(r / R)$ and decrease the velocity of its decline over time, as expected due to loss of microbial biomass (Bünemann et al., 2007). Therefore, autoclaving slightly affects the soil $P_{i}$ pool and most likely has minor effects on its abiotic sorption/desorption dynamics, whereas it inhibits biological reac- tions. Nonetheless, the effects of microbial lysis on $\mathrm{P}_{\mathrm{i}}$ sorption/desorption could be tested in sterile soils by adding increasing concentrations of non-labeled $\mathrm{P}_{\mathrm{i}}$ alongside the ${ }^{33} \mathrm{P}_{\mathrm{i}}$ tracer and then could be corrected for in future ${ }^{33} \mathrm{P}-\mathrm{IPD}$ experiments. As stated earlier, changes in the $\mathrm{P}_{\mathrm{i}}$ concentration caused by autoclaving can easily be accounted for in IPD approaches, as long as abiotic process rates remain unaffected by the treatment. However, the estimation of the contribution of abiotic and biotic processes is based on calculating the difference in P fluxes between sterile and non-sterile soils. This assumes that biotic and abiotic fluxes are additive while there is potential that both processes compete for available $\mathrm{P}_{\mathrm{i}}$. In this case we would overestimate abiotic process rates in autoclaved soils, due to lack of competition by biotic processes. This could effectively cause an underestimation of biotic processes, i.e., organic $\mathrm{P}$ mineralization and microbial $\mathrm{P}_{\mathrm{i}}$ uptake. To date we have no approach at hand to cope with this potential bias. Thus, overall, there is the potential for method improvement, particularly in terms of using abiotic controls circumventing autoclaving (e.g., bactericide combined with phosphomonoesterase inhibitors) or correcting for autoclaveinduced changes in aggregation and in soil $\mathrm{P}_{\mathrm{i}}$ content.

\subsection{Soil $P_{i}$ extraction using bicarbonate}

Similar to ${ }^{15} \mathrm{~N}$ IPD assays, where salt extractions are employed to target the available inorganic or organic $\mathrm{N}$ pool (Murphy et al., 2003; Wanek et al., 2010; Hu et al., 2017), we focused on the potentially bioavailable, salt-extractable $P_{i}$ pool that more suitably reflects the plant- (and microbial) accessible amount of soil $\mathrm{P}_{\mathrm{i}}$ (Fardeau et al., 1988; Olsen et al., 1954; Horta and Torrent, 2007) than the water extractable $\mathrm{P}_{\mathrm{i}}$ pool, which is mostly assessed with soil IEK methods. The applied $0.5 \mathrm{M} \mathrm{NaHCO}_{3}$ extraction ( $\mathrm{pH} 8.5$, Olsen $\mathrm{P}$ ) promotes the displacement of $\mathrm{P}_{\mathrm{i}}$ (and the extraction of labile $\mathrm{P}_{\mathrm{o}}$ ), particularly from Al-Fe (hydr)oxides and soil organic matter, by competition of bicarbonate anions with $\mathrm{P}_{\mathrm{i}}$. The underlying process is an increase of the negative charge on surfaces and a decrease of the concentration and activity of $\mathrm{Ca}^{2+}$ and $\mathrm{Al}^{3+}$, thereby increasing $\mathrm{P}$ solubility in acid to alkaline soils (Horta and Torrent, 2007; Schoenau and O'Halloran, 2008; Demaria et al., 2005). Several studies compared soil $P$ tests such as Bray III, resin $\mathrm{P}$ and Olsen $\mathrm{P}$ to soil water $\mathrm{P}_{\mathrm{i}}$ and plant $\mathrm{P}$ uptake in order to assess how well they reflect the available $\mathrm{P}_{\mathrm{i}}$ pool. These studies demonstrated that soil tests like bicarbonate extractions (Olsen P), resin P and DGT (diffusive gradients in thin films technique) closely resembled the $\mathrm{SA}$ values of $\mathrm{P}_{\mathrm{i}}$ extracted by water or $10 \mathrm{mM} \mathrm{CaSO}_{4}$ or from plants (Six et al., 2012; Fardeau et al., 1988; Demaria et al., 2005). Others further showed that isotopically exchangeable $\mathrm{P}_{\mathrm{i}}$ in soil water extracts ( $E$ values) and those extracted by plant roots in plant growth experiments ( $L$ values) were also strongly related (Bühler et al., 2003; Frossard et al., 1994). Bicarbonate extracted 8- to 22-fold greater amounts of exchangeable $\mathrm{P}_{\mathrm{i}}$ compared with water, and SA of $\mathrm{P}_{\mathrm{i}}$ in bicarbonate extracts 
reached $66 \%-90 \%$ of the SA values measured in soil water extracts (Demaria et al., 2005). IPD approaches require fast extractions to quickly terminate the assay after 4 and $24 \mathrm{~h}$, which renders water extractions (generally $16 \mathrm{~h}$ ), resin $\mathrm{P}$ (16h) and DGT (up to $48 \mathrm{~h}$ in low P soils; Six et al., 2012) impossible. Bicarbonate extractions only take 30-60 min and therefore represent a viable alternative. Moreover, it makes the IPD assay 8-fold more sensitive on average, as a greater amount of exchangeable $P_{i}$ is extracted by bicarbonate than with water (Kleinman et al., 2001). Underestimation of this labile $\mathrm{P}_{\mathrm{i}}$ pool - even if specific activities thereof are correctly measured - also causes underestimation of IPD rates, given that $P_{i}$ concentrations linearly affect IPD rates according to IPD Eqs. (1) and (2) above.

\subsection{Microbial P dynamics}

We observed very fast microbial $P_{i}$ immobilization in live soils (within minutes; extraction started directly after tracer addition), causing net immobilization of ${ }^{33} \mathrm{P}$ by $3 \%-38 \%$. Similar results were reported within 1.5 to $4 \mathrm{~h}$ by others, ranging from $6 \%$ to $37 \%$ (Bünemann et al., 2012; Kellogg et al., 2006). This has two major repercussions. (i) Rapid uptake might cause microbial $P_{i}$ assimilation and efflux or exudation of ${ }^{33} \mathrm{P}_{\mathrm{o}}$ metabolites without microbial death and turnover. However, the comparison between specific activities and ${ }^{33} \mathrm{P}$ recoveries of the direct measurement and after isobutanol fractionation (see below, and Fig. 3) showed that no significant release of microbial ${ }^{33} \mathrm{P}_{\mathrm{o}}$ occurred during the 24 and $48 \mathrm{~h}$ incubations. The short extraction times used in this study also decrease the likelihood of significant hydrolysis of $\mathrm{P}_{\mathrm{o}}$ compounds. (ii) Rapid microbial ${ }^{33} \mathrm{P}_{\mathrm{i}}$ uptake clearly rules out the use of $\mathrm{P}_{\mathrm{O}}$ mineralization assays that measure abiotic IEK in short-term batch experiments $(100 \mathrm{~min})$ without the addition of a microbicide or without prior sterilization and then extrapolate these "abiotic" process rates to the full experimental duration.

Microbial $P_{i}$ uptake can be derived indirectly as the difference in ${ }^{33} \mathrm{P}$ recovery between live and sterile soils (Fig. 5, this study), more directly by sECE (this study), or by parallel water or bicarbonate extraction with and without the addition of liquid chloroform or hexane (measuring resin strip or extractable $\mathrm{P}_{\mathrm{i}}$ ), or by chloroform fumigation extraction (Bünemann et al., 2012; Oberson et al., 2001; Oehl et al., 2001a; Spohn and Kuzyakov, 2013). Microbial net ${ }^{33} \mathrm{P}$ immobilization measured by direct $\mathrm{SECE}$ was higher relative to the difference in ${ }^{33} \mathrm{P}$ immobilized in live minus sterile soils, pointing towards (i) overestimation of microbial net ${ }^{33} \mathrm{P}$ immobilization by sECE due to incomplete extraction of nonmicrobial ${ }^{33} \mathrm{P}_{\mathrm{i}}$ by one-time bicarbonate extraction prior to sECE, or (ii) overestimation of abiotic sorption processes by autoclaving. In favor of (i), repeated extractions of soils with Bray 1 showed that soils continued to release $\mathrm{P}$ at lower rates in subsequent extractions after readily extractable $\mathrm{P}$ was removed by the first extraction (Serrasolsas et al., 2008; Mes- siga et al., 2014). Repeated extractions with bicarbonate also showed that the first extraction only removed $67 \%-78 \%$ of the ${ }^{33} \mathrm{P}_{\mathrm{i}}$ that was extractable with three consecutive extractions (D. Wasner, unpublished data, 2017). In favor of (ii), Kellogg et al. (2006) found higher net ${ }^{33} \mathrm{P}$ immobilization or sorption in sterile than in live soils. This was interpreted as a lack of microbial competition for $\mathrm{P}$ in sterile soils. However, we found a weak positive relationship $(R=0.749$, $P=0.087$; Table S1) between gross microbial $P_{\mathrm{i}}$ uptake and gross $P_{i}$ sorption. This opposes the idea of strong competition between sorption and microbial uptake on the basis of gross process measurements. Another possible mechanism underlying (ii) could be changes in soil structure and reactive surfaces enhancing soil $\mathrm{P}$ sorption. Delineation of the causes could be performed by a comparison of sECE with liquid chloroform-fumigation extraction (CFE), i.e., parallel assessments of microbial ${ }^{33} \mathrm{P}$ uptake, using a comparison of ${ }^{33} \mathrm{P}$ in bicarbonate versus bicarbonate + liquid chloroform or bicarbonate + liquid hexane extracts. Given the continued extraction of $\mathrm{P}_{\mathrm{i}}$ from exchangeable $\mathrm{P}_{\mathrm{i}}$ pools in serial extraction tests, parallel determination of microbial $\mathrm{P}$ and ${ }^{33} \mathrm{P}$ by $\mathrm{CFE}$ is recommended compared with sequential extractions by sECE.

\subsection{Comparison of isobutanol fractionation with direct measurements of $P_{i}$ and ${ }^{33} P$ activity}

We showed that ${ }^{33} \mathrm{P}$ IPD assays can be performed specifically on the $\mathrm{P}_{\mathrm{i}}$ pool using isobutanol fractionation in high$\mathrm{P}$ soils. However, due to low production or persistence of ${ }^{33} \mathrm{P}_{\mathrm{o}}$, results closely conformed with measurements run without $\mathrm{P}_{\mathrm{i}}-\mathrm{P}_{\mathrm{o}}$ fractionation by malachite green and direct ${ }^{33} \mathrm{P}_{\text {total }}$ estimates. This was ascertained for forest soils from French Guiana and Costa Rica, and for grassland soils from Austria and Germany (data not shown for French Guiana and Germany). Isobutanol fractionation has previously been applied in radiotracer studies on P dynamics in soils (Kellogg et al., 2006) and litter (Mooshammer et al., 2012) to ascertain the separation of $\mathrm{P}_{\mathrm{i}}$ from any possible radiolabeled $\mathrm{P}_{\mathrm{o}}$ contaminant, although without comparison to SA in unfractionated bicarbonate extracts. Oehl et al. (2001a) also applied isobutanol fractionation to water extracts of fumigated and control soils, demonstrating that with long extraction times $(16 \mathrm{~h}){ }^{33} \mathrm{P}_{\mathrm{i}}$ activities in water extracts with and without isobutanol fractionation were comparable. It was suggested that ${ }^{33} \mathrm{P}_{\mathrm{o}}$ possibly released during fumigation was cleaved by soil phosphatases during extraction. This may not apply for shortterm extractions (e.g., $0.5 \mathrm{M} \mathrm{NaHCO}_{3}$ for $30 \mathrm{~min}$, as used in this study) where hydrolysis by phosphatases would not necessarily occur due to short contact times. Measurements of ${ }^{33} \mathrm{P}$ isotope pool dilution in soils based on bicarbonate extracts can therefore be interchangeably be performed by (i) direct measurements of ${ }^{33} \mathrm{P}_{\text {tot }}$ and $\mathrm{P}_{\mathrm{i}}$ in acidified bicarbonate extracts and after (ii) isobutanol fractionation on ${ }^{33} \mathrm{P}_{\mathrm{i}}$ and $\mathrm{P}_{\mathrm{i}}$. However, this needs to be validated for other types of soil, 
and may change significantly after longer incubation periods (weeks), when microbial ${ }^{33} \mathrm{P}_{\mathrm{i}}$ uptake, assimilation and turnover causes the release of ${ }^{33} \mathrm{P}_{\mathrm{o}}$ into the soil. The shortcut of performing direct measurements of $\mathrm{P}_{\mathrm{i}}$ concentration and ${ }^{33} \mathrm{P}$ in acidified bicarbonate extracts comes along with a 4- to 10-fold greater sensitivity of the malachite green assay relative to phosphomolybdate blue measurements of soil $P_{i}$. Another option to increase the measurement sensitivity for $\mathrm{P}_{\mathrm{i}}$ (and possibly also for ${ }^{33} \mathrm{P}_{\mathrm{i}}$ ) for strongly sorbing low$\mathrm{P}$ soils has been adopted by Randriamanantsoa et al. (2013), and is based on the concentration of the phosphomolybdate blue complex from a large volume of extract into a smaller volume of hexane, with subsequent phase separation (Murphy and Riley, 1962). This allows for the quantification limits of $\mathrm{P}_{\mathrm{i}}$ to be decreased 66-fold compared with the classical Murphy-Riley protocol, and 14-fold compared with the malachite green procedure (Randriamanantsoa et al., 2013), but involves the handling of large volumes of radiolabeled extracts.

\subsection{Time kinetics}

During the first few minutes, equilibration between the tracer and tracee was not achieved, which was indicated by the enhanced extractability of the added tracer $\left({ }^{33} \mathrm{P}_{\mathrm{i}}\right)$ relative to more strongly bonded native tracee (soil exchangeable $\mathrm{P}_{\mathrm{i}}$ ). The fast process of equilibration caused very rapid declines in the SA of $\mathrm{P}_{\mathrm{i}}$ during the first few minutes. Thereafter, microbial uptake and soil $\mathrm{P}$ fixation caused a rapid drawdown of extractable ${ }^{33} \mathrm{P}_{\mathrm{i}}$ and a further decrease in the SA of soil $\mathrm{P}_{\mathrm{i}}$, while soil $P_{i}$ concentrations did not change after the initial phase of tracer-tracee equilibration (Fig. 4). These processes slowed down within the first $1-2 \mathrm{~h}$ but did not cease, and declines in ${ }^{33} \mathrm{P}$ recoveries and in the $\mathrm{SA}$ of $\mathrm{P}_{\mathrm{i}}$ occurred throughout the incubation period, in sterile as well as in live soils. Thereafter, time kinetics of IPD were relatively constant between 4 and $24 \mathrm{~h}$ for both temperate and tropical soils, as shown by the linearity of the relationship in a plot of $\ln$ (SA of $P_{i}$ ) versus time. This linear relationship is conceptually different from the plot of $\log$ (recovery, $r / R$ ) versus $\log$ (time) in short-term IEK batch experiments, which provides the parameter " $n$ ", i.e., the slope or the rate of decline in tracer recovery due to sorption over time (Bünemann, 2015). Based on constant IPD rates in the abovementioned time interval we advise running ${ }^{33} \mathrm{P}$ pool dilution experiments for an incubation period of 4 to $24 \mathrm{~h}$. This time frame is well within the linear range, as it lies after the rapid abiotic equilibration, and is long enough to allow significant pool dilution to occur for sensitive measurements of organic $\mathrm{P}$ mineralization. Longer incubation times are not recommended due to the risk of ${ }^{33} \mathrm{P}_{\mathrm{o}}$ release from dying microbes, potentially causing a ${ }^{33} \mathrm{P}_{\mathrm{i}}$ reflux via remineralization, violating a major assumption of IPD theory.

\subsection{Comparison of $P_{0}$ mineralization rates with published values}

The detection limit of the IPD approach was $0.12 \mu \mathrm{P} \mathrm{g}^{-1}$ soil $\mathrm{dw} \mathrm{d}^{-1}$. In comparison, the detection limits for gross $\mathrm{P}_{\mathrm{o}}$ mineralization by the IEK approach were $0.20 \mu \mathrm{g} \mathrm{g}^{-1}$ soil dw d $\mathrm{d}^{-1}$ using the modified protocol including the hexane concentration of phosphomolybdate blue for tropical soils (Randriamanantsoa et al., 2015) and 0.6$2.6 \mu \mathrm{P} \mathrm{g}^{-1}$ soil $\mathrm{dw} \mathrm{d}^{-1}$ using the traditional IEK approach on temperate soils (Bünemann et al., 2007). Values of gross $\mathrm{P}_{\mathrm{o}}$ mineralization measured via IPD in this study ranged between 0.08 and $0.15 \mu \mathrm{g} \mathrm{g} \mathrm{g}^{-1}$ soil dw d ${ }^{-1}$ in tropical forest soils and $0.48-2.03 \mu \mathrm{g} \mathrm{P} \mathrm{g}^{-1}$ soil $\mathrm{dw} \mathrm{d}^{-1}$ in temperate grassland soils and were, therefore, well within the range of those compiled for IEK measurements by Bünemann (2015) for 14 different soils, including temperate arable, grassland and forest soils $\left(0.1-12.6 \mu \mathrm{g} \mathrm{g} \mathrm{g}^{-1}\right.$ soil $\left.\mathrm{dw} \mathrm{d}^{-1}\right)$ and one tropical arable soil $\left(0.8 \mu \mathrm{g} \mathrm{P} \mathrm{g}^{-1}\right.$ soil $\left.\mathrm{dw} \mathrm{d}^{-1}\right)$. To date, the highest gross $\mathrm{P}_{\mathrm{o}}$ mineralization rates have been reported for decomposing beech litter, i.e., $22.5-86.3 \mu \mathrm{g} \mathrm{P} \mathrm{g}^{-1}$ soil litter $\mathrm{dw} \mathrm{d}^{-1}$ (Mooshammer et al., 2012). A direct comparison of the present IPD and the IEK approaches on the same soils might help to clarify how far the approaches really deviate or converge in their gross $\mathrm{P}_{\mathrm{o}}$ mineralization rate estimates.

\subsection{Physicochemical and biological controls on soil $P_{i}$ processes}

We found that gross $P_{o}$ mineralization was strongly positively correlated with total soil $\mathrm{P}$ but not to soil organic $\mathrm{P}$, soil organic $\mathrm{C}$, soil texture or soil acid phosphatase activity. This indicates that gross $\mathrm{P}_{\mathrm{o}}$ mineralization might be driven by total $\mathrm{P}$ rather than by soil enzyme activity, and that total soil $P_{o}$ does not represent the $P_{o}$ fraction accessible to soil phosphatases well. A few studies have demonstrated positive correlations between gross $P_{0}$ mineralization and soil $\mathrm{P}_{\mathrm{o}}$ (Lopez-Hernandez et al., 1998) or litter $\mathrm{P}_{\mathrm{o}}$ (or its inverse C:P; Mooshammer et al., 2012). However, Wyngaard et al. (2016) did not find this relationship between gross $P_{0}$ mineralization and total soil $\mathrm{P}_{\mathrm{o}}$; however, they did note a relation with the $\mathrm{P}_{\mathrm{o}}$ content of the coarse soil fraction, which points in a similar direction to our results. Moreover, $\mathrm{P}_{\mathrm{O}}$ mineralization might rather be controlled by soil phosphodiesterases targeting DNA, RNA, teichoic acids and phospholipids, than by phosphomonoesterases that are responsible for the final extracellular dephosphorylation of $\mathrm{P}_{0}$. In contrast to our results, positive relationships were found between gross $\mathrm{P}_{\mathrm{o}}$ mineralization and phosphomonoesterase activities in two studies (Spohn et al., 2013; Oehl et al., 2004), although not across studies (Bünemann, 2015). Thus, a larger set of soils varying in soil $\mathrm{pH}$, texture and mineralogy might provide better insights into the controls of soil $\mathrm{P}_{\mathrm{o}}$ mineralization, such as effects by extracellular phosphatase activity (phosphomonoesterases and phosphodiesterases), and the 
availability, stabilization and accessibility of organic $\mathrm{P}$ in soils, among others. Moreover, high $\mathrm{P}_{\mathrm{i}}$ availability (i.e., bicarbonate $\mathrm{P}_{\mathrm{i}}$ ) strongly suppressed phosphomonoesterase activity in soils, causing a negative correlation between the enzyme activity and extractable $\mathrm{P}_{\mathrm{i}}$. In contrast, extractable $\mathrm{P}_{\mathrm{i}}$ was positively related to gross $P_{o}$ mineralization, indicating that high- $\mathrm{P}_{\mathrm{i}}$ conditions suppressed phosphatase production but not $\mathrm{P}_{\mathrm{o}}$ mineralization across these soils. This was also found as a positive correlation between gross $\mathrm{P}_{0}$ mineralization and water-extractable $\mathrm{P}_{\mathrm{i}}$ by others (Schneider et al., 2017).

The contribution of gross $\mathrm{P}_{\mathrm{o}}$ mineralization to total $\mathrm{P}_{\mathrm{i}}$ supply including $P_{i}$ desorption from exchangeable $P_{i}$ pools and dissolution ranged between $25 \%$ and $74 \%$, with a trend towards larger contributions in low-P tropical soils (35\%$74 \%)$ compared with temperate soils $(25 \%-51 \%)$. This clearly demonstrates that biological processes contribute importantly to the $\mathrm{P}_{\mathrm{i}}$ supply in soils, particularly in low-P soils, as also pointed out by Bünemann (2015). In low-P forest soils biological processes were shown to dominate over physicochemical processes, while in P-rich forest soils abiotic processes controlled gross $P_{i}$ supply rates (Bünemann et al., 2016). It was also found that the contributions of microbial processes decreased with soil depth, whereas in deep soils diffusive fluxes (i.e., gross $\mathrm{P}_{\mathrm{i}}$ desorption) dominated the soil $\mathrm{P}_{\mathrm{i}}$ supply due to low total $\mathrm{P}_{\mathrm{o}}$ contents relative to total $\mathrm{P}$ (Achat et al., 2012, 2013).

Gross abiotic $P_{i}$ release rates via desorption and dissolution were strongly positively related to total soil $\mathrm{P}$ and bicarbonate $\mathrm{P}_{\mathrm{i}}$, but not to other parameters such as soil $\mathrm{pH}$, soil texture and soil organic $\mathrm{C}$ content. In contrast to the weak effects of soil $\mathrm{pH}$ and texture on gross soil $\mathrm{P}_{\mathrm{i}}$ supply, soil mineralogy and particularly oxalate-extractable $\mathrm{Fe}$ and $\mathrm{Al}$ as proxies for $\mathrm{Fe}-\mathrm{Al}$ (hydr)oxides play a major role in controlling abiotic dynamics of phosphate ions in soils, across the full range from acidic to alkaline soils (Achat et al., 2016). $\mathrm{Fe}-\mathrm{Al}$ (hydr)oxides provide large positively-charged surface areas in weathered soils that are highly reactive to phosphate ions, more so than clay minerals such as kaolinite, illite and others (Hinsinger, 2001; Regelink et al., 2015). Therefore, soil mineralogy might provide further interesting insights into the controls of abiotic processes as demonstrated by (Achat et al., 2011, 2016), but can also affect $P_{o}$ mineralization via strong effects on the sorption strength of organic matter and of $\mathrm{P}_{\mathrm{o}}$ compounds. Moreover, the positive relations of $\mathrm{P}_{\mathrm{i}}$ availability and $\mathrm{P}_{\mathrm{i}}$ desorption with soil organic $\mathrm{C}$ contents reported elsewhere has been explained by competitive sorption of $\mathrm{P}_{\mathrm{i}}$ and SOC or DOC to reactive surfaces such as positively charged metal (hydr)oxides (Regelink et al., 2015; Achat et al., 2016).

Gross $\mathrm{P}_{\mathrm{i}}$ sorption rates exceeded gross $\mathrm{P}_{\mathrm{i}}$ desorption rates approximately 2 -fold but both were strongly related, indicating close and rapid cycling of available $\mathrm{P}_{\mathrm{i}}$ through sorption/desorption processes. The observed rates indicate that soils immobilized more $P_{i}$ then they mobilized by abiotic processes, causing an intermediate drawdown of available $P_{i}$ pools. Two processes work against this drawdown of $P_{i}$ in soils, i.e., $\mathrm{P}_{\mathrm{O}}$ mineralization and microbial $\mathrm{P}$ release via turnover and lysis. Moreover, plants (and microbes) might also desorb this sorbed $\mathrm{P}_{\mathrm{i}}$ by the release of phytosiderophores and organic acids and thereby replenish $\mathrm{P}_{\mathrm{i}}$ and reinject it into the organic $\mathrm{P}$ cycle. Similar to the soil $\mathrm{C}-\mathrm{N}$ cycle, we might also expect an active "bank mechanism" regulating nutrient and C sequestration in soils (Fontaine et al., 2011). At high nutrient availability priming effects are low, allowing the sequestration of nutrients and SOC buildup. At low nutrient availability microbes (and plants) release nutrients from SOM and from mineral surfaces stimulated by root exudates, effectively mining inorganic and organic $\mathrm{P}$ stored in soils.

The strong positive relationship between gross $P_{i}$ sorption rates and soil total $\mathrm{P}$, soil total $\mathrm{P}_{\mathrm{i}}$ and bicarbonate soil $\mathrm{P}_{i}$, and the lack of a relationship with soil $\mathrm{pH}$, soil organic $\mathrm{C}$, clay content and soil texture highlights again that specific soil minerals, particularly metal (hydr)oxides and to a lesser extent clay minerals such kaolinite, which are factors not fully captured by soil $\mathrm{pH}$ and soil texture alone, are responsible for $P_{i}$ sorption in soils (Regelink et al., 2015). In the IEK experiments it was found that the rate of abiotic $P_{i}$ depletion from soil solution via sorption was positively related to $\mathrm{Al}-\mathrm{Fe}$ (hydr)oxide content and negatively related to soil organic $\mathrm{C}$ divided by the $\mathrm{Al}$ and $\mathrm{Fe}$ oxide content (Achat et al., 2016; Tran et al., 1988). The strong negative relation between abiotic net $\mathrm{P}_{\mathrm{i}}$ immobilization and soil $\mathrm{pH}$ reconfirms that strongly weathered, acid tropical soils have a higher $\mathrm{P}$ sorption and fixation capacity than temperate soils.

Finally, gross microbial $P_{i}$ uptake rates were directly proportional to microbial biomass $P$ measured by sECE. We also found greater $P_{i}$ immobilization potentials through sorptive reactions $(28 \%-92 \%)$ than through biological sinks $(5 \%-$ $37 \%$ ) in the soils studied here. The importance of the rapid net uptake of tracer by soil microbes has also been demonstrated by other studies (e.g., Bünemann et al., 2012). However, the presented IPD approach allowed for the estimation of gross rates of microbial $P_{i}$ uptake in addition to net microbial $P_{i}$ immobilization for the first time. Gross rates of microbial uptake were calculated from the IPD approach, not necessitating the application of any extraction factor to calculate microbial biomass $\mathrm{P}$ from chloroform-labile $\mathrm{P}\left(k_{\mathrm{EP}}-\right.$ factor). The use of extraction factors becomes necessary when studying net $P_{i}$ uptake over prolonged time periods in tracer experiments and for the correction of net $\mathrm{P}_{\mathrm{o}}$ mineralization rates (Bünemann, 2015; Bünemann et al., 2007).

\subsection{Conclusion and outlook}

The combination of this IPD assay with advanced numerical modeling approaches, as applied by Müller and Bünemann (2014), might further enhance the precision of estimates of simultaneously occurring soil P-cycle processes and thereby advance the knowledge of major controls of 
the transformations and fluxes of this important nutrient in terrestrial ecosystems. There is an ever-increasing need for high-quality data on soil $\mathrm{P}$ processes, even more so to calibrate terrestrial biogeochemical models and incorporate nutrient controls on plant productivity in global models. This IPD approach may provide highly important quantitative data to implement soil P-cycling processes into global biogeochemical models. This will further enhance our current understanding of nutrient controls on the global terrestrial C cycle and improve our capabilities to predict future changes by increasing discrepancies in $\mathrm{N}$ and $\mathrm{P}$ inputs into the terrestrial biosphere.

Data availability. The data of the different experiments are freely available upon request from the corresponding author.

Supplement. The supplement related to this article is available online at: https://doi.org/10.5194/bg-16-3047-2019-supplement.

Author contributions. The project was conceived and supervised by WW. DZ, JP and DW performed the measurements and data evaluation. WW wrote the paper with contributions from all coauthors.

Competing interests. The authors declare that they have no conflict of interest.

Acknowledgements. We are indebted to the Isotope Laboratory managers for access and training (Virginie Canoine, Markus Schmid).

Review statement. This paper was edited by Sébastien Fontaine and reviewed by two anonymous referees.

\section{References}

Achat, D. L., Bakker, M. R., Saur, E., Pellerin, S., Augusto, L., and Morel, C.: Quantifying gross mineralisation of $\mathrm{P}$ in dead soil organic matter: Testing an isotopic dilution method, Geoderma, 158, 163-172, https://doi.org/10.1016/j.geoderma.2010.04.027, 2010.

Achat, D. L., Augusto, L., Morel, C., and Bakker, M. R.: Predicting available phosphate ions from physical-chemical soil properties in acidic sandy soils under pine forests, J. Soils Sediments, 11, 452-466, https://doi.org/10.1007/s11368-010-0329-9, 2011.

Achat, D. L., Augusto, L., Bakker, M. R., Gallet-Budynek, A., and Morel, C.: Microbial processes controlling $\mathrm{P}$ availability in forest spodosols as affected by soil depth and soil properties, Soil Biol. Biochem., 44, 39-48, https://doi.org/10.1016/j.soilbio.2011.09.007, 2012.
Achat, D. L., Bakker, M. R., Augusto, L., and Morel, C.: Contributions of microbial and physical-chemical processes to phosphorus availability in Podzols and Arenosols under a temperate forest, Geoderma, 211, 18-27, https://doi.org/10.1016/j.geoderma.2013.07.003, 2013.

Achat, D. L., Pousse, N., Nicolas, M., Bredoire, F., and Augusto, L.: Soil properties controlling inorganic phosphorus availability: general results from a national forest network and a global compilation of the literature, Biogeochemistry, 127, 255-272, https://doi.org/10.1007/s10533-015-0178-0, 2016.

Alphei, J. and Scheu, S.: Effects of biocidal treatments on biological and nutritional properties of a mull-structured woodland soil, Geoderma, 56, 435-448, https://doi.org/10.1016/00167061(93)90125-5, 1993.

Anderson, B. H. and Magdoff, F. R.: Autoclaving soil samples affects algal-available phosphorus, J. Environ. Qual., 34, 19581963, https://doi.org/10.2134/jeq2005.0024, 2005.

Berns, A. E., Philipp, H., Narres, H. D., Burauel, P., Vereecken, H., and Tappe, W.: Effect of gamma-sterilization and autoclaving on soil organic matter structure as studied by solid state NMR, UV and fluorescence spectroscopy, Eur. J. Soil Sci., 59, 540-550, https://doi.org/10.1111/j.1365-2389.2008.01016.x, 2008.

Blankinship, J. C., Becerra, C. A., Schaeffer, S. M., and Schimel, J. P.: Separating cellular metabolism from exoenzyme activity in soil organic matter decomposition, Soil Biol. Biochem., 71, 68 75, https://doi.org/10.1016/j.soilbio.2014.01.010, 2014.

Booth, M. S., Stark, J. M., and Rastetter, E.: Controls on nitrogen cycling in terrestrial ecosystems: A synthetic analysis of literature data, Ecol. Monogr., 75, 139-157, 2005.

Braun, J., Mooshammer, M., Wanek, W., Prommer, J., Walker, T. W. N., Rutting, T., and Richter, A.: Full N-15 tracer accounting to revisit major assumptions of N-15 isotope pool dilution approaches for gross nitrogen mineralization, Soil Biol. Biochem., 117, 16-26, https://doi.org/10.1016/j.soilbio.2017.11.005, 2018.

Bühler, S., Oberson, A., Sinaj, S., Friesen, D. K., and Frossard, E.: Isotope methods for assessing plant available phosphorus in acid tropical soils, Eur. J. Soil Sci., 54, 605-616, https://doi.org/10.1046/j.1365-2389.2003.00542.x, 2003.

Bünemann, E. K., Marschner, P., McNeill, A. M., and McLaughlin, M. J.: Measuring rates of gross and net mineralisation of organic phosphorus in soils, Soil Biol. Biochem., 39, 900-913, https://doi.org/10.1016/j.soilbio.2006.10.009, 2007.

Bünemann, E. K., Oberson, A., Liebisch, F., Keller, F., Annaheim, K. E., Huguenin-Elie, O., and Frossard, E.: Rapid microbial phosphorus immobilization dominates gross phosphorus fluxes in a grassland soil with low inorganic phosphorus availability, Soil Biol. Biochem., 51, 84-95, https://doi.org/10.1016/j.soilbio.2012.04.012, 2012.

Bünemann, E. K.: Assessment of gross and net mineralization rates of soil organic phosphorus - A review, Soil Biol. Biochem., 89, 82-98, https://doi.org/10.1016/j.soilbio.2015.06.026, 2015.

Bünemann, E. K., Augstburger, S., and Frossard, E.: Dominance of either physicochemical or biological phosphorus cycling processes in temperate forest soils of contrasting phosphate availability, Soil Biol. Biochem., 101, 85-95, https://doi.org/10.1016/j.soilbio.2016.07.005, 2016.

Carter, D. O., Yellowlees, D., and Tibbett, M.: Autoclaving kills soil microbes yet soil enzymes remain active, Pedobiologia, 51, 295-299, https://doi.org/10.1016/j.pedobi.2007.05.002, 2007. 
Condron, L. M., Moir, J. O., Tiessen, H., and Stewart, J. W. B.: Critical-Evaluation Of Methods For Determining Total Organic Phosphorus In Tropical Soils, Soil Sci. Soc. Am. J., 54, 1261-1266, https://doi.org/10.2136/sssaj1990.03615995005400050010x, 1990.

D’Angelo, E., Crutchfield, J., and Vandiviere, M.: Rapid, sensitive, microscale determination of phosphate in water and soil, J. Environ. Qual., 30, 2206-2209, 2001.

Demaria, P., Flisch, R., Frossard, E., and Sinaj, S.: Exchangeability of phosphate extracted by four chemical methods, J. Plant Nutr. Soil Sc., 168, 89-93, https://doi.org/10.1002/jpin.200421463, 2005.

Di, H. J., Condron, L. M., and Frossard, E.: Isotope techniques to study phosphorus cycling in agricultural and forest soils: A review, Biol. Fertil. Soils, 24, 1-12, https://doi.org/10.1007/bf01420213, 1997.

Di, H. J., Cameron, K. C., and McLaren, R. G.: Isotopic dilution methods to determine the gross transformation rates of nitrogen, phosphorus, and sulfur in soil: a review of the theory, methodologies, and limitations, Aust. J. Soil Res., 38, 213-230, 2000.

Fardeau, J. C., Morel, C., and Boniface, R.: Why the Olsen method should be used to estimate available soil phosphorus?, Agronomie, 8, 577-584, https://doi.org/10.1051/agro:19880702, 1988.

Fardeau, J. C., Morel, C., and Boniface, R.: Phosphate Ion Transfer From Soil To Soil Solution - Kinetic-Parameters, Agronomie, 11, 787-797, https://doi.org/10.1051/agro:19910909, 1991.

Fardeau, J. C.: Le phosphore assimilable des sols : sa représentation par un modèle fonctionnel à plusieurs compartiments Agronomie, 13, 317-331, 1993.

Fontaine, S., Henault, C., Aamor, A., Bdioui, N., Bloor, J. M. G., Maire, V., Mary, B., Revaillot, S., and Maron, P. A.: Fungi mediate long term sequestration of carbon and nitrogen in soil through their priming effect, Soil Biol. Biochem., 43, 86-96, https://doi.org/10.1016/j.soilbio.2010.09.017, 2011.

Frossard, E., Fardeau, J. C., Brossard, M., and Morel, J. L.: Soil isotopically exchangeable phosphorus - a comparison between E and L-values, Soil Sci. Soc. Am. J., 58, 846-851, 1994.

Frossard, E., Achat, D. L., Bernasconi, S. M., Bünemann, E. K., Fardeau, J. C., Jansa, J., Morel, C., Rabeharisoa, L., Randriamanantsoa, L., Sinaj, S., Tamburini, F., and Oberson, A.: The Use of Tracers to Investigate Phosphate Cycling in Soil-Plant Systems, in: Phosphorus in Action: Biological Processes in Soil Phosphorus Cycling, edited by: Bunemann, E. K., Oberson, A., and Frossard, E., Soil Biology, 59-91, 2011.

Goldberg, S. and Sposito, G.: On the mechanism of specific phosphate-adsorption by hydroxylated mineral surfaces - a review, Commun. Soil Sci. Plant Anal., 16, 801-821, https://doi.org/10.1080/00103628509367646, 1985.

Green, V. S., Stott, D. E., and Diack, M.: Assay for fluorescein diacetate hydrolytic activity: Optimization for soil samples, Soil Biol. Biochem., 38, 693-701, https://doi.org/10.1016/j.soilbio.2005.06.020, 2006.

Hart, S. C., Nason, G. E., Myrold, D. D., and Perry, D. A.: Dynamics of gross nitrogen transformations in an old-growth forest: the carbon connection, Ecology, 75, 880-891, 1994.

Hinsinger, P.: Bioavailability of soil inorganic P in the rhizosphere as affected by root-induced chemical changes: a review, Plant
Soil, 237, 173-195, https://doi.org/10.1023/a:1013351617532, 2001.

Horta, M. D. and Torrent, J.: The Olsen P method as an agronomic and environmental test for predicting phosphate release from acid soils, Nutr. Cycl. Agroecosys., 77, 283-292, https://doi.org/10.1007/s10705-006-9066-2, 2007.

Hu, Y. T., Zheng, Q., and Wanek, W.: Flux Analysis of Free Amino Sugars and Amino Acids in Soils by Isotope Tracing with a Novel Liquid Chromatography/High Resolution Mass Spectrometry Platform, Anal. Chem., 89, 9192-9200, https://doi.org/10.1021/acs.analchem.7b01938, 2017.

Jayachandran, K., Schwab, A. P., and Hetrick, B. A. D.: Partitioning dissolved inorganic and organic phosphorus using acidified molybdate and isobutanol, Soil Sci. Soc. Am. J., 56, 762-765, 1992.

Kedi, B., Sei, J., Quiquampoix, H., and Staunton, S.: Persistence of catalytic activity of fungal phosphatases incubated in tropical soils, Soil Biol. Biochem., 56, 69-74, https://doi.org/10.1016/j.soilbio.2012.02.005, 2013.

Kellogg, L. E., Bridgham, S. D., and Lopez-Hernandez, D.: A comparison of four methods of measuring gross phosphorus mineralization, Soil Sci. Soc. Am. J., 70, 1349-1358, https://doi.org/10.2135/sssaj2005.0300, 2006.

Kirkham, D. and Bartholomew, W. V.: Equations for following nutrient transformations in soil, utilizing tracer data, Soil Sci. Soc. Am. Pro., 18, 33-34, 1954.

Kleinman, P. J. A., Sharpley, A. N., Gartley, K., Jarrell, W. M., Kuo, S., Menon, R. G., Myers, R., Reddy, K. R., and Skogley, E. O.: Interlaboratory comparison of soil phosphorus extracted by various soil test methods, Commun. Soil Sci. Plan, 32, 2325-2345, https://doi.org/10.1081/css-120000376, 2001.

Lopez-Hernandez, D., Brossard, M., and Frossard, E.: P-isotopic exchange values in relation to $\mathrm{P}_{\mathrm{O}}$ mineralisation in soils with very low P-sorbing capacities, Soil Biol. Biochem., 30, 1663-1670, https://doi.org/10.1016/s0038-0717(97)00255-1, 1998.

Lotrario, J. B., Stuart, B. J., Lam, T., Arands, R. R., Oconnor, O. A., and Kosson, D. S.: Effects Of Sterilization Methods On The Physical Characteristics Of Soil - Implications For Sorption Isotherm Analyses, B. Environ. Contam. Tox., 54, 668-675, 1995.

Mander, C., Wakelin, S., Young, S., Condron, L., and O'Callaghan, M.: Incidence and diversity of phosphatesolubilising bacteria are linked to phosphorus status in grassland soils, Soil Biol. Biochem., 44, 93-101, https://doi.org/10.1016/j.soilbio.2011.09.009, 2012.

Marx, M. C., Wood, M., and Jarvis, S. C.: A microplate fluorimetric assay for the study of enzyme diversity in soils, Soil Biol. Biochem., 33, 1633-1640, 2001.

Messiga, A. J., Ba, Y. X., Ziadi, N., Belanger, G., and Lafond, J.: Assessing the depletion of soil $\mathrm{P}$ following sequential extractions with Mehlich-3 and Olsen solutions, Arch. Agron. Soil Sci., 60, 1445-1458, https://doi.org/10.1080/03650340.2014.884709, 2014.

Miller, W. and Miller, D.: A micropipette method for soil mechanical analysis, Commun. Soil Sci. Plan, 18, 1-15, 1987.

Mooshammer, M., Wanek, W., Schnecker, J., Wild, B., Leitner, S., Hofhansl, F., Blochl, A., Hammerle, I., Frank, A. H., Fuchslueger, L., Keiblinger, K. M., Zechmeister-Boltenstern, S., and Richter, A.: Stoichiometric controls of nitrogen and phosphorus 
cycling in decomposing beech leaf litter, Ecology, 93, 770-782, 2012.

Mooshammer, M., Hofhansl, F., Frank, A. H., Wanek, W., Hammerle, I., Leitner, S., Schnecker, J., Wild, B., Watzka, M., Keiblinger, K. M., Zechmeister-Boltenstern, S., and Richter, A.: Decoupling of microbial carbon, nitrogen, and phosphorus cycling in response to extreme temperature events, Sci. Adv., 3, e1602781, https://doi.org/10.1126/sciadv.1602781, 2017.

Müller, C. and Bünemann, E. K.: A P-33 tracing model for quantifying gross $\mathrm{P}$ transformation rates in soil, Soil Biol. Biochem., 76, 218-226, https://doi.org/10.1016/j.soilbio.2014.05.013, 2014.

Murphy, D. V., Recous, S., Stockdale, E. A., Fillery, I. R. P., Jensen, L. S., Hatch, D. J., and Goulding, K. W. T.: Gross nitrogen fluxes in soil: Theory, measurement and application of $15 \mathrm{~N}$ pool dilution techniques, Adv. Agron., 79, 69-118, 2003.

Murphy, J. and Riley, J. P.: A modified single solution method for determination of phosphate in natural waters, Anal. Chim. Acta, 26, 31-36, 1962.

O'Halloran, I. P., and Cade-Menun, B. J.: Total and Organic Phosphorus, chap. 24, in: Soil Sampling and Methods of Analysis, 2nd edn., edited by: Carter, M. R. and Gregorich, E. G., CRC Press, Taylor \& Francis, Boca Raton, FL, USA, 265-291, 2008.

Oberson, A., Friesen, D. K., Rao, I. M., Buhler, S., and Frossard, E.: Phosphorus Transformations in an Oxisol under contrasting landuse systems: The role of the soil microbial biomass, Plant Soil, 237, 197-210, https://doi.org/10.1023/a:1013301716913, 2001.

Oehl, F., Oberson, A., Probst, M., Fliessbach, A., Roth, H. R., and Frossard, E.: Kinetics of microbial phosphorus uptake in cultivated soils, Biol. Fertil. Soils, 34, 31-41, 2001a.

Oehl, F., Oberson, A., Sinaj, S., and Frossard, E.: Organic phosphorus mineralization studies using isotopic dilution techniques, Soil Sci. Soc. Am. J., 65, 780-787, 2001b.

Oehl, F., Frossard, E., Fliessbach, A., Dubois, D., and Oberson, A.: Basal organic phosphorus mineralization in soils under different farming systems, Soil Biol. Biochem., 36, 667-675, https://doi.org/10.1016/j.soilbio.2003.12.010, 2004.

Ohno, T. and Zibilske, L. M.: Determination of low concentrations of phosphorus in soil extracts using malachite green, Soil Sci. Soc. Am. J., 55, 892-895, 1991.

Olsen, S. R., Cole, C. V., Watanabe, F. S., and Dean, L. A.: Estimation of Available Phosphorus in Soils by Extraction with Sodium Bicarbonate, USDA Circ. 939, US Government Printing Office, Washington, DC, 1954.

Penuelas, J., Sardans, J., Rivas-Ubach, A., and Janssens, I. A.: The human-induced imbalance between $\mathrm{C}, \mathrm{N}$ and $\mathrm{P}$ in Earth's life system, Glob. Change Biol., 18, 3-6, https://doi.org/10.1111/j.13652486.2011.02568.x, 2012.

Penuelas, J., Poulter, B., Sardans, J., Ciais, P., van der Velde, M., Bopp, L., Boucher, O., Godderis, Y., Hinsinger, P., Llusia, J., Nardin, E., Vicca, S., Obersteiner, M., and Janssens, I. A.: Human-induced nitrogen-phosphorus imbalances alter natural and managed ecosystems across the globe, Nat. Commun., 4, 2934, https://doi.org/10.1038/ncomms3934, 2013.

Randhawa, P. S., Condron, L. M., Di, H. J., Sinaj, S., and McLenaghen, R. D.: Effect of green manure addition on soil organic phosphorus mineralisation, Nutr. Cycl. Agroecosyst., 73, 181189, https://doi.org/10.1007/s10705-005-0593-z, 2005.

Randriamanantsoa, L., Morel, C., Rabeharisoa, L., Douzet, J. M., Jansa, J., and Frossard, E.: Can the isotopic ex- change kinetic method be used in soils with a very low water extractable phosphate content and a high sorbing capacity for phosphate ions?, Geoderma, 200, 120-129, https://doi.org/10.1016/j.geoderma.2013.01.019, 2013.

Randriamanantsoa, L., Frossard, E., Oberson, A., and Bünemann, E. K.: Gross organic phosphorus mineralization rates can be assessed in a Ferralsol using an isotopic dilution method, Geoderma, 257, 86-93, https://doi.org/10.1016/j.geoderma.2015.01.003, 2015.

Reed, S. C., Yang, X. J., and Thornton, P. E.: Incorporating phosphorus cycling into global modeling efforts: a worthwhile, tractable endeavor, New Phytol., 208, 324-329, https://doi.org/10.1111/nph.13521, 2015.

Regelink, I. C., Weng, L., Lair, G. J., and Comans, R. N. J.: Adsorption of phosphate and organic matter on metal (hydr)oxides in arable and forest soil: a mechanistic modelling study, Eur. J. Soil Sci., 66, 867-875, https://doi.org/10.1111/ejss.12285, 2015.

Richardson, A. E. and Simpson, R. J.: Soil Microorganisms Mediating Phosphorus Availability, Plant Physiol., 156, 989-996, https://doi.org/10.1104/pp.111.175448, 2011.

Ryan, P. R., Delhaize, E., and Jones, D. L.: Function and mechanism of organic anion exudation from plant roots, Annu. Rev. Plant Physiol. Plant Molec. Biol., 52, 527-560, https://doi.org/10.1146/annurev.arplant.52.1.527, 2001.

Salonius, P. O., Robinson, J. B., and Chase, F. E.: A Comparison Of Autoclaved And Gamma-Irradiated Soils As Media For Microbial Colonization Experiments, Plant Soil, 27, 239-248, https://doi.org/10.1007/bf01373392, 1967.

Schneider, K. D., Voroney, R. P., Lynch, D. H., Oberson, A., Frossard, E., and Bünemann, E. K.: Microbiallymediated $\mathrm{P}$ fluxes in calcareous soils as a function of water-extractable phosphate, Soil Biol. Biochem., 106, 51-60, https://doi.org/10.1016/j.soilbio.2016.12.016, 2017.

Schnurer, J. and Rosswall, T.: Fluorescein diacetate hydrolysis as a measure of total microbial activity in soil and litter, Appl. Environ. Microbiol., 43, 1256-1261, 1982.

Schoenau, J. J. and O'Halloran, I. P.: Sodium BicarbonateExtractable Phosphorus, in: Soil Sampling and Methods of Analysis, edited by: Carter, M. R. and Gregorich, E. G., CRC Press, Boca Raton, FL, 89-94, 2008.

Serrasolsas, I. and Khanna, P. K.: Changes in heated and autoclaved forest soils of SE Australia, 2. Phosphorus and phosphatase activity, Biogeochemistry, 29, 25-41, 1995a.

Serrasolsas, I. and Khanna, P. K.: Changes in heated and autoclaved forest soils of SE Australia, 1. Carbon and nitrogen, Biogeochemistry, 29, 3-24, 1995b.

Serrasolsas, I., Romanya, J., and Khanna, P. K.: Effects of heating and autoclaving on sorption and desorption of phosphorus in some forest soils, Biol. Fertil. Soils, 44, 1063-1072, https://doi.org/10.1007/s00374-008-0301-7, 2008.

Setia, R., Verma, S. L., and Marschner, P.: Measuring microbial biomass carbon by direct extraction - Comparison with chloroform fumigation-extraction, Eur. J. Soil Biol., 53, 103-106, https://doi.org/10.1016/j.ejsobi.2012.09.005, 2012.

Shin, Y.-J., Kwak, J. I., and An, Y.-J.: Evidence for the inhibitory effects of silver nanoparticles on the activities of soil exoenzymes, Chemosphere, 88, 524-529, https://doi.org/10.1016/j.chemosphere.2012.03.010, 2012. 
Sirova, D., Rejmankova, E., Carlson, E., and Vrba, J.: Current standard assays using artificial substrates overestimate phosphodiesterase activity, Soil Biol. Biochem., 56, 75-79, https://doi.org/10.1016/j.soilbio.2012.02.008, 2013.

Six, L., Pypers, P., Degryse, F., Smolders, E., and Merckx, R.: The performance of DGT versus conventional soil phosphorus tests in tropical soils - An isotope dilution study, Plant Soil, 359, 267279, https://doi.org/10.1007/s11104-012-1192-9, 2012.

Skipper, H. D. and Westermann, D. T.: Comparative effects of propylene oxide, sodium azide, and autoclaving on selected soil properties, Soil Biol. Biochem., 5, 409-414, 1973.

Spohn, M., Ermak, A., and Kuzyakov, Y.: Microbial gross organic phosphorus mineralization can be stimulated by root exudates A P-33 isotopic dilution study, Soil Biol. Biochem., 65, 254-263, https://doi.org/10.1016/j.soilbio.2013.05.028, 2013.

Spohn, M. and Kuzyakov, Y.: Phosphorus mineralization can be driven by microbial need for carbon, Soil Biol. Biochem., 61, 69-75, https://doi.org/10.1016/j.soilbio.2013.02.013, 2013.

Tanaka, S., Kobayashi, T., Iwasaki, K., Yamane, S., Maeda, K., and Sakurai, K.: Properties and metabolic diversity of microbial communities in soils treated with steam sterilization compared with methyl bromide and chloropicrin fumigations, Soil Sci. Plant Nutr., 49, 603-610, 2003.

Tiwari, S. C., Tiwari, B. K., and Mishra, R. R.: Enzyme activities in soils - effects of leaching, ignition, autoclaving and fumigation, Soil Biol. Biochem., 20, 583-585, https://doi.org/10.1016/00380717(88)90079-x, 1988.

Tran, T. S., Fardeau, J. C., and Giroux, M.: Effects of soil properties on plant-available phosphorus determined by the isotopic dilution phosphorus-32 method, Soil Sci. Soc. Am. J., 52, 13831390, 1988.
Turner, B. L., Condron, L. M., Richardson, S. J., Peltzer, D. A., and Allison, V. J.: Soil organic phosphorus transformations during pedogenesis, Ecosystems, 10, 1166-1181, 2007.

Vitousek, P. M. and Farrington, H.: Nutrient limitation and soil development: Experimental test of a biogeochemical theory, Biogeochemistry, 37, 63-75, 1997.

Wanek, W., Mooshammer, M., Blöchl, A., Hanreich, A., and Richter, A.: Determination of gross rates of amino acid production and immobilization in decomposing leaf litter by a novel ${ }^{15} \mathrm{~N}$ isotope pool dilution technique, Soil Bio. Biochem., 42, 1293-1302, 2010.

Wolf, D. C., Dao, T. H., Scott, H. D., and Lavy, T. L.: Influence of sterilization methods on selected soil microbiological, physical, and chemical properties, J. Environ. Qual., 18, 39-44, 1989.

Wyngaard, N., Cabrera, M. L., Jarosch, K. A., and Bünemann, E. K.: Phosphorus in the coarse soil fraction is related to soil organic phosphorus mineralization measured by isotopic dilution, Soil Biol. Biochem., 96, 107-118, https://doi.org/10.1016/j.soilbio.2016.01.022, 2016.

Yang, X. and Post, W. M.: Phosphorus transformations as a function of pedogenesis: A synthesis of soil phosphorus data using Hedley fractionation method, Biogeosciences, 8, 2907-2916, https://doi.org/10.5194/bg-8-2907-2011, 2011.

Yang, X., Post, W. M., Thornton, P. E., and Jain, A.: The distribution of soil phosphorus for global biogeochemical modeling, Biogeosciences, 10, 2525-2537, https://doi.org/10.5194/bg-102525-2013, 2013. 